\title{
Computational Analysis of Cortical Neuronal Excitotoxicity in a Large Animal Model of Neonatal Brain Injury
}

\section{Panagiotis Kratimenos}

Children's National Research Institute

\section{Abhya Vij}

The George Washington University School of Medicine and Health Sciences

\section{Robinson Vidva}

Digirobi Solutions

\section{loannis Koutroulis}

Children's National Research Institute

\section{Maria Delivoria-Papadopoulos}

Drexel University College of Medicine

\section{Vittorio Gallo}

Children's National Research Institute

\section{Aaron Sathyanesan ( $\nabla$ asathyanesan@childrensnational.org )}

Children's National Research Institute https://orcid.org/0000-0002-9226-7831

\section{Research}

Keywords: neonatal brain injury, excitotoxicity, Src kinase, calcium/calmodulin, nuclear calcium, computational modeling, SimBiology

Posted Date: November 2nd, 2021

DOI: https://doi.org/10.21203/rs.3.rs-1021777/v1

License: (a) (1) This work is licensed under a Creative Commons Attribution 4.0 International License. Read Full License 


\section{Abstract}

Background: Neonatal hypoxic brain injury is a major cause of intellectual and developmental disability. Hypoxia causes neuronal dysfunction and death in the developing cerebral cortex due to excitotoxic $\mathrm{Ca}^{2+}$ influx. In the translational piglet model of hypoxic encephalopathy, we have previously shown that hypoxia overactivates $\mathrm{Ca}^{2+} /$ Calmodulin (CaM) signaling via Sarcoma ( $\mathrm{Src}$ ) kinase in cortical neurons, resulting in overexpression of proapoptotic genes. However, identifying the exact relationship between alterations in neuronal $\mathrm{Ca}^{2+}$-influx, molecular determinants of cell death, and the degree of hypoxia in a dynamic system represents a significant challenge.

Methods: We used experimental and computational methods to identify molecular events critical to the onset of excitotoxicity-induced apoptosis in the cerebral cortex of newborn piglets. We used 2-3 day-old piglets (normoxic [Nx], hypoxic [Hx], and hypoxic + Src-inhibitor-treatment [Hx+PP2]groups) for biochemical analysis of ATP production, $\mathrm{Ca}^{2+}$-influx, and $\mathrm{Ca}^{2+} / \mathrm{CaM}$-dependent protein kinase kinase 2(CaMKK2) expression. We then used SimBiology to build a computational model of the $\mathrm{Ca}^{2+} / \mathrm{CaM}-\mathrm{Src}-$ kinase signaling cascade, simulating $\mathrm{Nx}, \mathrm{Hx}$, and $\mathrm{Hx}+\mathrm{PP} 2$ conditions. To evaluate our model, we used Sobol variance decomposition, multiparametric global sensitivity analysis, and parameter scanning.

Results: Our model captures important molecular trends caused by hypoxia in the piglet brain. Incorporating the action of Src kinase inhibitor PP2 further validated our model and enabled predictive analysis of the effect of hypoxia on CaMKK2. We determined the impact of a feedback loop related to Src phosphorylation of NMDA receptors and activation kinetics of CaMKII. We also identified distinct modes of signaling wherein $\mathrm{Ca}^{2+}$ level alterations following Src kinase inhibition may not be a linear predictor of changes in Bax expression. Importantly, our model indicates that while pharmacological pre-treatment significantly reduces the onset of abnormal $\mathrm{Ca}^{2+}$-influx, there exists a window of intervention after hypoxia during which targeted modulation of Src-NMDAR interaction kinetics in combination with PP2 administration can reduce $\mathrm{Ca}^{2+}$-influx and Bax expression to similar levels as pre-treatment.

Conclusions: Our model identifies new dynamics of critical components in the $\mathrm{Ca}^{2+} / \mathrm{CaM}-\mathrm{Src}$ signaling pathway leading to neuronal injury and provides an essential framework for drug efficacy studies in translational models of neonatal brain injury for the prevention of intellectual and developmental disabilities.

\section{Background}

Cerebral hypoxia in neonates is a potent driver of excitotoxic neuronal injury that often leads to cell death[1]. Neuronal death during this early developmental period causes long-term alterations in neural circuits, resulting in poor intellectual and developmental outcomes later in life[2]. However, only few targeted therapeutic strategies currently exist to prevent or ameliorate excitotoxicity and associated neuronal injury to the neonatal cerebral cortex, due to the lack of mechanistically detailed studies in translationally-relevant models of neonatal brain injury [3]. 
Neuronal excitotoxicity is strongly linked to abnormal $\mathrm{Ca}^{2+}$ influx due to uncontrolled glutamatergic drive[4]. The canonical understanding of neuronal excitotoxicity suggests that a sustained disruption of $\mathrm{Ca}^{2+}$ homeostasis, due to overactivity of ionotropic N-methyl D-aspartate (NMDA) and a-amino-3-hydroxy5-methyl-4-isoxazolepropionic acid (AMPA)/kainate receptors, eventually leads to the onset of mitochondrial-dependent or independent cell death pathways [2]. In this framework, cell death is a consequence of an overload on neuronal $\mathrm{Ca}^{2+}$ buffering systems[5], such as the $\mathrm{Ca}^{2+} / \mathrm{CaM}$ signaling cascade[6, 7]. Evidence for this framework draws from hypoxic injury in the adult brain. However, injury during the neonatal period is complex, due to the effects of multiple signaling cascades related to both physiological development and/or pathology being differentially affected[8]. As a result, the specific mechanisms that link overloaded $\mathrm{Ca}^{2+}$ buffering to the onset of cell-death-related gene expression have not yet been precisely and systematically defined in the context of neonatal injury of the cerebral cortex.

Past efforts to rescue brain-hypoxia-induced excitotoxic mechanisms have been focused on preventing abnormal $\mathrm{Ca}^{2+}$ influx by targeting the ionotropic mode of NMDAR activity $[9,10]$. These efforts have largely been unsuccessful $[9,11]$. While targeting the ionotropic mode of NMDAR activity has not succeeded in clinical trials, emerging evidence points to another avenue for therapeutic intervention in hypoxic neuronal injury: non-ionotropic or quasi-metabotropic modes of NMDAR function[12]. In particular, the interaction between sarcoma ( $\mathrm{Src}$ ) kinase and NMDARs shows significant potential as a therapeutic target in ameliorating the effect of excitotoxic mechanisms induced by hypoxic insult to neurons[13]. Since Src kinase and its family members (Src family kinases; SFKs) also interact with ionotropic modes of NMDA function in non-pathological contexts [14], potential cross-talk could exist between Src and the two modes of NMDAR function.

In a translationally-relevant piglet model of neonatal brain injury, we have established that hypoxia triggers $\mathrm{Ca}^{2+}$ influx into both the cytoplasm and nucleus [15]. $\mathrm{Ca}^{2+}$ influx leads to the formation of the activated $\mathrm{Ca}^{2+/} \mathrm{CaM}$ complex, which subsequently leads to the activation and translocation of $\mathrm{Ca}^{2+} / \mathrm{CaM}$ dependent protein kinase IV (CaMKIV) to the nucleus, resulting in cyclic-AMP response element binding protein (CREB)-mediated transcription of proapoptotic genes $B a x$ and $B c / 2[16,17]$. Studies from other mammalian models have shown that $\mathrm{Ca}^{2+}$ influx into the nucleus also directly modulates CREB-mediated gene regulation through CaMKIV[18]. We have also shown that Src kinase is a critical component of $\mathrm{Ca}^{2+}$ dependent transcription of proapoptotic genes in the piglet model[19]. Pharmacological pretreatment of hypoxic piglets with PP2, a potent Src inhibitor, has a protective effect, keeping many of the $\mathrm{Ca}^{2+} / \mathrm{CaM}$ signaling components at normoxic levels and partially preventing the activation of CREB[19], further keeping the apoptotic machinery under control.

The failure to rescue the effect of excitotoxic mechanisms by solely focusing on NMDAR antagonism underscores the need for unified and integrated mechanistic approaches to determine effective therapeutics tailored to specific pathological and developmental contexts, such as neonatal hypoxic brain injury. While we have biochemically measured individual components of the $\mathrm{Ca}^{2+} / \mathrm{CaM}-\mathrm{Src}$ pathway in normoxic, hypoxic, and treatment conditions, the relative importance of specific steps and reaction 
kinetics has not been explored. Further, we have not explored the potential role of other components in this and other convergent pathways which may be critical to overall $\mathrm{Ca}^{2+}$ homeostasis and cell-deathrelated processes. Therefore, in order to study a unified signaling pathway from receptor activationmediated $\mathrm{Ca}^{2+}$ influx to proapoptotic protein expression, we built a computational model of the $\mathrm{Ca} 2+/ \mathrm{CaM}$-Src pathway. We calibrated our model using our previously published experimental data from the piglet model of neonatal brain injury and validated it using newly obtained experimental data on another critical yet unexplored component of the pathway: CaMKK2 in normoxic and hypoxic conditions. Additionally, we further validated our model based on findings from other groups using the piglet model of neonatal brain injury. Simulations of our model indicate dissociable states between $\mathrm{Ca}^{2+}$ influx and Bax expression. Global sensitivity analysis reveals relative robustness to changes in concentration of CaMKIV, but significant sensitivity to glutamatergic hyperstimulation and activated CREB, suggesting an important role for convergent pathways in linking increased excitatory drive to apoptosis. Finally, our model provides a mechanistic basis for using interventions targeted to the feedback loop between Src and NMDAR.

\section{Methods}

\section{Model construction}

We constructed the computational model using the SimBiology Model Builder Interface (SimBiology version 6.1, Mathworks Inc., Natick, MA). A representation of our model is presented in Figure 1. Our model has four discrete compartments, each of which was considered well-mixed: extracellular space, cytoplasm with plasma membrane, nucleus with nuclear membrane, endoplasmic reticulum with endoplasmic reticulum membrane, and mitochondria. The model was built in a modular fashion, and contains 7 integrated sub-models with their regulatory components:

1. Calcium sub-model, including NMDA receptor (NMDAR), voltage gated $\mathrm{Ca}^{2+}$ channel (VGCC), $\mathrm{Ca}^{2+}$ permeable AMPA receptor (CP-AMPAR), IP3-Ca channel, SERCA channel, Ryr channel, and Na-Ca exchanger (NCX)

2. Src kinase sub-model with regulatory components

3. Oxygen-ATP sub-model

4. $\mathrm{Ca}^{2+} / \mathrm{CaM}$ cytoplasmic signaling cascade sub-model with regulatory components

5. $\mathrm{Ca}^{2+} / \mathrm{CaM}$ nuclear signaling sub-model with regulatory components

6. PKC-Raf-MEK-ERK pathway

7. CREB-Creb binding protein (CBP) regulation of Bax transcription 
The complete model was composed of 62 species, 134 reaction parameters, and 63 individual reactions. Reactions were modeled as either activation enzymatic reactions, where the enzyme $E$ activates the molecule $A$ at rate $k_{\text {act }}$ to yield $A_{\text {active: }}$ :

$\mathrm{A}+\mathrm{E} \stackrel{\mathrm{k}_{\mathrm{act}}}{\longrightarrow} \mathrm{A}_{\text {active }}+\mathrm{E}(1)$

or inactivation reactions, when $A_{\text {active }}$ is inactivated at rate $k_{\text {inact }}$ :

$A_{\text {active }} \stackrel{k_{\text {inact }}}{\longrightarrow} A(2)$

or binding/unbinding reactions, when $A$ binds to molecule $B$ to yield $A B$ at rate $k_{b i n d}$, and unbinds at rate $\mathrm{k}_{\text {unbind: }}$

$\mathrm{A}+\mathrm{B} \stackrel{\mathrm{k}_{\text {bind }}}{\longrightarrow} \mathrm{AB}(3)$

$\mathrm{AB} \stackrel{\mathrm{k}_{\text {unbind }}}{\longrightarrow} \mathrm{A}+\mathrm{B}(4)$

or translocation/transport reactions, where A translocates from the cytoplasm into the nucleus at rate $\mathrm{k}_{\text {in }}$ and translocates out at rate $\mathrm{k}_{\text {out }}$ :

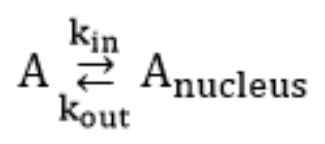

Ordinary differential equations (ODEs), starting quantities, and fluxes for reactions are listed in the Supplementary material. The initial species concentrations were derived or estimated from other published models, our lab's data, and from conversion of label-free quantification signal intensity from localization data on PepTracker[20] to protein counts using the Perseus 'Proteomics Microruler' plugin[21].

\section{Simulation of hypoxia, normoxia, and pharmacological intervention}

We modeled conditions of normoxia ( $\mathrm{Nx}$ ) and hypoxia $(\mathrm{Hx})$ by modifying the extracellular concentration of $\mathrm{O}_{2}$. Per Tuckerman et al., 2004 in normoxia, the intracellular $\mathrm{O}_{2}$. concentration in tissues is 10,000 $40,000 \mathrm{ppm}$, in moderate hypoxia, $\left[\mathrm{O}_{2}\right]=1,000-10,000 \mathrm{ppm}$, and in severe hypoxia $\left[\mathrm{O}_{2}\right]=0-1000 \mathrm{ppm}[22]$. Assuming a solvent density of $1 \mathrm{~g} / \mathrm{mol}$, these values correspond to $312.5-1250 \mathrm{mM}, 31.25-312.5 \mathrm{mM}$, and 0-31.25 mM respectively. We used "Events" in the SimBiology model builder interface to set discrete transitions between $\mathrm{Nx}, \mathrm{Hx}$, and intervention with the Src-inhibitor PP2 ( $\mathrm{Hx}+\mathrm{PP} 2)$. We set the hypoxic event trigger as time $\geq 120 \mathrm{~s}$, with the event function lowering the extracellular $\mathrm{O}_{2}$ concentration to 3.25 $\mu \mathrm{M}$. In the second event, we maintained $\mathrm{Hx}$, but introduced PP2 at a concentration of $1 \mu \mathrm{M}$. For model input during $\mathrm{Nx}$, we dosed extracellular glutamate at the amount defined by the parameter "stim", for 12 pulses, with a 10 s inter-pulse interval. During $\mathrm{Hx}$ and $\mathrm{Hx}+\mathrm{PP} 2$, we dosed extracellular glutamate at the amount defined by "hyperstim" delivering 48 pulses with a $5 \mathrm{~s}$ inter-pulse interval. 
Global sensitivity analysis (GSA) and multiparametric global sensitivity analysis (MPGSA)

We used the Global Sensitivity Analysis app[23] to perform GSA on our model and compute Sobol indices[24,25]. We set the number of samples to 1000 , and the output time to match the duration of our simulation: 0-360 s at a resolution of $1 \mathrm{~s}$. The "interp1q" Interpolation method was used. Following computation of Sobol indices, the same simulations were reused for MPGSA with specific cut-offs for observables. Significance level was set at 0.05 .

\section{Experimental procedures}

The experiments and the reporting data are performed and published in accordance to the ARRIVE (Animal Research: Reporting of In Vivo Experiments) guidelines[26]. Fifteen newborn Yorkshire piglets (postnatal day 2 to 3; Willow Glenn Farm, Strasburg, PA) were studied. Animals were similar at baseline clinical characteristics. Animals were housed in standard cages and were exposed to 12-hour light/ 12hour dark cycle. Access to standard newborn formula and water was provided during study ad libitum. The experimental protocol was approved by the Institutional Animal Care and Use Committee of Drexel University (IACUC protocol \#200491). All methods were performed in accordance with the relevant guidelines and regulations. Appropriate use of drugs in standardized dosage was followed during experiments to reduce or eliminate pain, according to the $\mathrm{NIH}$ Guidelines for the Care and Use of Laboratory Animals[27]. Anesthesia was induced with $4 \%$ Isoflurane and maintained with $0.8-1 \%$ Isoflurane. The piglets were intubated within $10 \mathrm{~min}$ of induction of anesthesia and were placed on a pressure ventilator using a mixture of $75 \%$ nitrous oxide and $25 \%$ oxygen. Fluids and medication were administered using a peripheral intravenous catheter. Fentanyl $(25 \mu \mathrm{g} / \mathrm{kg})$ and pancuronium bromide $(0.1$ $\mathrm{mg} / \mathrm{kg}$ ) were administered through the intravenous route.

Following baseline ventilation with normal blood gases for a period of 1 hour, animals were randomly assigned to either a normoxic $(\mathrm{Nx})$, hypoxic $(\mathrm{Hx})$ or hypoxic treatment groups $(\mathrm{Hx}+\mathrm{PP} 2)$ by means of block randomization[28]. Hypoxia was induced by a gradual decrease of the $\mathrm{FiO}_{2}$ to 0.06 and maintenance at this level for 1 hour.

Following 1 hour of hypoxia, the cerebral cortex was harvested. Anesthesia and analgesia were maintained throughout hypoxia and brain harvesting through rapid midsagittal craniotomy. The parenchyma was flash-frozen in liquid nitrogen and stored at $-80^{\circ} \mathrm{C}$ for further biochemical analysis. The piglets were maintained at $38-39^{\circ} \mathrm{C}$ (normothermic). No animal died during the application of hypoxia. For the animals in treatment group, Src-inhibitor PP2 $(1 \mathrm{mg} / \mathrm{kg}, \mathrm{IV})$ was administered a half-hour before $\mathrm{Hx}$.

\section{Isolation of Cerebral Cortical Neuronal Nuclei}

The isolation procedure for the cerebral cortical nuclei was based on the method of Giuffrida et al. [29]. 1 gram of brain tissue was homogenized in 15 volumes of a medium containing $0.32 \mathrm{M}$ sucrose, $10 \mathrm{mM}$ Tris- $\mathrm{HCl}$ and $1 \mathrm{mM} \mathrm{MgCl} 2$ ( $\mathrm{pH}$ 6.8). The resulting homogenate was then filtered through a nylon bolting 
mesh (size $110 \mathrm{~lm}$ ) and subjected to centrifugation at $850 \mathrm{~g}$ for $10 \mathrm{~min}$. To increases the yield of large neuronal nuclei, the homogenate was passed through a discontinuous gradient with a final sucrose concentration of $2.1 \mathrm{M}$, followed by another centrifugation step at 70,000 $\mathrm{g}$ for 1 hour. The nuclear pellet was then collected and re-homogenized. Purity of neuronal nuclei was ensured by phase contrast microscopy. Protein content was determined according to Lowry et al. [30]

\section{Isolation of the Cytosolic Fraction}

One gram of cerebral cortical tissue was homogenized by a Dounce homogenizer (seven strokes with pestle clearance $0.15 \mathrm{~mm}$ and seven strokes with pestle clearance $0.07 \mathrm{~mm}$ ) in $30 \mathrm{ml}$ of fresh isolation medium (0.32 M sucrose, $1 \mathrm{mM}$ EDTA, $20 \mathrm{mM}$ Tris-HCl buffer, $\mathrm{pH}$ 7.1). The homogenate was then subjected to centrifugation at $1500 \mathrm{~g}$, followed by a second centrifugation step at $15000 \mathrm{~g}$ for 10 minutes. The supernatant was finally centrifuged at $100000 \mathrm{~g}$ for an hour to obtain the cytosolic fraction and the protein concentration was determined.

\section{Western Blot Analysis}

Total protein extraction was performed in cell lysis buffer (0.5\% NP-40, 0.5\% SDS, $1.5 \mathrm{mM} \mathrm{pH} \mathrm{7.4} \mathrm{Tris-}$ $\mathrm{HCL}, 15 \mathrm{mM} \mathrm{NaCl}$ ). Following electrophoresis (20 $\mathrm{gg}$ protein/lane) and polyvinylidene difluoride (PVDF) membrane transfer, primary antibody incubation was performed against Calcium Calmodulin Kinase dependent Kinase 2 [Sigma rabbit Anti-CAMKK2, Catalog\# HPA017389, 1:500 dilution] overnight at $4^{\circ} \mathrm{C}$ on a rocking platform. The membranes were treated with goat-anti-rabbit HRP-conjugated secondary antibodies (Invitrogen Thermo Fisher, Waltham, Massachusetts, USA). The target protein bands were determined using the reagents visualized provided in the ECL+ plus kit (GE Healthcare, Piscataway, NJ, USA). The immunoreactive band intensities were analyzed by imaging densitometry (GS 700 Imaging Densitometer, Bio-Rad) using ImageJ (National Institutes of Health, Bethesda, MD, USA). The protein expression is presented as optical density (OD) per $\mathrm{mm}^{2}$.

\section{Determination of ATP levels}

Energy failure caused by hypoxia in cerebral cortex tissue was confirmed by determining the levels of ATP based on an assay previously described in detail [31,32]. Briefly, frozen cortical tissue was powdered under liquid nitrogen in $6 \% \mathrm{w} / \mathrm{v}$ perchloric acid, thawed on ice and then centrifuged at $2000 \mathrm{~g}$ for 15 minutes at $4^{\circ} \mathrm{C}$. The supernatant was neutralized using 2.23 M Potassium Carbonate $/ 0.5 \mathrm{M}$ triethanolamine/50 mM EDTA buffer $(\mathrm{pH} 7.3)$ and then subjected to centrifugation at $2000 \mathrm{~g}$ for 15 minutes at $4^{\circ} \mathrm{C} .300 \mu \mathrm{l}$ of the supernatant was added to $1 \mathrm{ml}$ of buffer $(50 \mathrm{mM}$ triethanolamine, $5 \mathrm{mM}$ $\mathrm{MgCl} 2,2 \mathrm{mM}$ EDTA, $2 \mathrm{mM}$ glucose, $\mathrm{pH}$ 7.6) and $20 \mu \mathrm{NADP}(10 \mathrm{mg} / \mathrm{ml}$ in $50 \mathrm{mM}$ triethanolamine (TRA)$\mathrm{HCl}$ buffer). Samples were incubated for 8 minutes with Glucose-6-phosphate dehydrogenase and read, following which Hexokinase was added and absorbance measured until steady state was reached. ATP concentration was calculated from the increase in absorbance at $340 \mathrm{~nm} .20 \mu \mathrm{l}$ each of ADP

\section{Nuclear $\mathrm{Ca}^{2+}$ Concentration}


Neuronal nuclei $(150 \mu \mathrm{g})$ were incubated in $300 \mu \mathrm{l}$ medium composed of $50 \mathrm{mM}$ Tris buffer $(\mathrm{pH} 7.4), 1$ $\mu \mathrm{M} 45 \mathrm{Ca}^{2+}$, and $1 \mathrm{mM}$ ATP. The $\mathrm{Ca}^{2+}$ influx assay was carried out at $37^{\circ} \mathrm{C}$ for 2 minutes. Samples were then filtered on a glass fiber filter and washed three times in $20 \mathrm{mM}$ Tris (pH 7.2), $100 \mathrm{mM}$ potassium chloride buffer. A Rackbeta scintillation counter (Pharmacia, Gaithersburg, MD, USA) was used to measure radioactivity.

\section{Statistical Analysis}

Statistical analysis for experimental measurements was performed using Graphpad Prism v. 9. We used Ordinary one-way ANOVA with Tukey post-hoc multiple comparisons test. A P-value of less than 0.05 was considered statistically significant.

\section{Results}

\section{CaMKK2 expression is reduced due to neonatal hypoxic brain injury}

CaMKIV critically controls activity-dependent gene transcription in neurons [33]. We have previously shown that CaMKIV expression is significantly upregulated by neonatal hypoxic brain injury[34]. CaMKIV activity is strongly activated by CaMKK2 [33]. However, it remains unknown if CaMKK2 expression is also altered by to neonatal hypoxic brain injury. In order to identify the effect of hypoxia on the cerebral cortex, we first confirmed tissue hypoxia by measuring ATP (Figure 2a). ATP was significantly reduced in both the $\mathrm{Hx}(\mathrm{n}=5)$ and $\mathrm{Hx}+\mathrm{PP} 2$ group $(\mathrm{n}=3)$ compared to Nx controls $(\mathrm{n}=5)$ (One-way ANOVA - overall: F $(2$, 10) $=89.02, \mathrm{P}<0.0001$; Tukey comparison Nx vs. Hx: P< 0.0001; Tukey comparison Nx vs. Hx + PP2: P< 0.0001 ). We also confirmed $\mathrm{Ca}^{2+}$ influx into neuronal nuclei (Figure $2 \mathrm{~b}$ ), which increased in the $\mathrm{Hx}$ group (Overall one-way ANOVA: F $(2,14)=32.94 ; \mathrm{P}<0.0001$; Tukey comparison Nx vs. Hx: $\mathrm{P}<0.0001$ ). PP2 treatment reduced hypoxic-injury induced $\mathrm{Ca}^{2+}$ influx (Tukey comparison $\mathrm{Hx}$ vs. $\mathrm{Hx}+\mathrm{PP2}$ : $\mathrm{P}=0.0116$ ), however, $\mathrm{Ca}^{2+}$ levels in the $\mathrm{Hx}+\mathrm{PP} 2$ group were still significantly higher than $\mathrm{Nx}$ (Tukey comparison Nx vs. $\mathrm{Hx}+\mathrm{PP2}: \mathrm{P}<0.0001$ ), indicative of a partial rescue. Western blot analysis (Figure $2 \mathrm{c}$ ) revealed that CaMKK2 expression significantly increased in the $\mathrm{Hx}$ group (Figure 2d; overall One-way ANOVA: $\mathrm{F}(2,15)$ $=19.68 ; \mathrm{P}<0.0001$; Tukey comparison: Nx vs. Hx: $\mathrm{P}=0.0004)$. However, in contrast to $\mathrm{Ca}^{2+}$ influx, CaMKK2 expression was restored to almost-normoxic levels (Tukey comparison: $\mathrm{Hx}$ vs. $\mathrm{Hx}+\mathrm{PP2}: \mathrm{P}=$ $0.0002 ; \mathrm{Nx}$ vs. $\mathrm{Hx}+\mathrm{PP} 2: \mathrm{P}=0.9336$ ). We used the changes in $\mathrm{Ca}^{2+}$ influx and alterations in CaMKK2 expression for both validation and predictive analysis for our computational model.

\section{Model validation and predictive analysis of pharmacological intervention with PP2}

We simulated model response to the input glutamate pulses under $\mathrm{Nx}, \mathrm{Hx}$, and $\mathrm{Hx}+\mathrm{PP} 2$ conditions (Figure 3). In accordance with previous experimental results, our model captured an increase in activated Src (Figure 4a), nuclear CaMKIV (Figure 4b), cytoplasmic and nuclear $\mathrm{Ca}^{2+}$ (Figure 4c), and Bax 
expression (Figure 4d) induced by $\mathrm{Hx}$ (dashed line at $\mathrm{t}=120 \mathrm{~s}$ ), and a decrease in concentration following Src-inhibtion with PP2 (dashed line at $\mathrm{t}=240 \mathrm{~s}$ ). We validated our model with previously published data from Delivoria-Papadopoulos et al. (2011) [16] and from new data obtained from experiments we performed (Figure 2; Table 1). Experimental trends for pharmacological intervention with PP2 matched trends between experimental data obtained from the piglet model and simulation results, with an effect accuracy of $40.22 \%$ for nuclear $\mathrm{Ca}^{2+}, 69.01 \%$ for activated $\mathrm{Ca}^{2+} / \mathrm{CaM}, 89.56 \%$ for activated CaMKIV, and 47.56\% for activated CREB (Table 1). While our model overestimated PP2 effect accuracies for nuclear $\mathrm{Ca} 2+$, activated CaMKIV, and activated CREB, it underestimated the PP2 effect for activated $\mathrm{Ca}^{2+} / \mathrm{CaM}$. We then attempted to predict changes in alterations in CaMKK2 between $\mathrm{Hx}$ and $\mathrm{Hx}+\mathrm{PP} 2$ conditions. Our analysis slightly underestimated the effect of PP2 intervention with an accuracy of $99.0 \%$. Thus, based on the validation of our model, we proceeded to use it for further evaluation of perturbations to intracellular signaling induced by neonatal brain injury.

\section{Global sensitivity analysis}

We computed Sobol indices to analyze sensitivity of our model to changes in species concentration [25]. Based on literature and previously published results, we included "stim", "hyperstim", NMDAR, CREB, and nuclear CaMKIV, as input parameters. We varied parameters from $0.25 \mathrm{X}$ to $1.75 \mathrm{X}$ of starting concentrations. Observables included nuclear $\mathrm{Ca}^{2+}$ and Bax expression. Since we sought to measure both individual contributions of particular species parameters as well as interaction effects between parameters, we plotted first order and total order Sobol indices for model responses against simulation time course (Figure 5). We observed that, for Bax expression, stim (Nx glutamate pulse concentration; Figure 5a, top panel), hyperstim ( $\mathrm{Hx}$ glutamate pulse concentration, Figure $5 \mathrm{a}$, second-from-top panel), and CREB (Figure 5a, fourth-from-top pane) displayed obvious first order non-zero indices. Additionally, total order indices for these parameters were higher than the corresponding first order indices (Figure $5 b$ ), indicating interaction between species parameters. Additionally, the fraction of unexplained variance (Figure 5a, bottom-most panel) increased following the onset of $\mathrm{Hx}$ (grey vertical line at $\mathrm{t}=2 \mathrm{~min}$ ). Nuclear CaMKIV total order indices during PP2 intervention (grey vertical line at $t=4 \mathrm{~min}$ ) are slightly higher than first order indices during the same time period, indicating the presence of interaction with other parameters. Surprisingly, for nuclear $\mathrm{Ca}^{2+}$ influx, only hyperstim showed slight interaction with other parameters (Figure 5c-d). Specifically, within a few seconds following $\mathrm{Hx}$ onset, the fraction of unexplained variance indicated a slight transient increase. Thus, GSA for the chosen parameters indicates that our model is robust to changes in concentration of certain species including NMDAR and nuclear CaMKIV but is responsive to changes in normoxic and excitotoxic glutamate pulse concentration and CREB concentration. Importantly, these parameters interact such that there are differential effects on Bax expression and $\mathrm{Ca}^{2+}$ influx.

\section{Multi-parametric global sensitivity analysis}

In order to identify the particular conditions where input parameters of the GSA have differential effects on $\mathrm{Ca} 2+$ influx and Bax expression, we plotted all the simulations from the GSA (Figure 6a). Two 
simulations revealed the dissociation between Bax expression and $\mathrm{Ca}^{2+}$ influx following PP2 administration (Figure 6a, simulations [dotted lines] marked by asterisks in top and bottom panels). Since there was a discrete threshold above which simulations showed $\mathrm{Ca}^{2+}$-influx-Bax dissociation, we defined a classifier for multi-parametric global sensitivity analysis (MPGSA) based on a threshold for maximum values per simulation (maximum value $>10 \mu \mathrm{M}$ for nuclear $\mathrm{Ca}^{2+}$ influx and maximum value $>1 \mu \mathrm{M}$ for Bax expression). We reused the Sobol indices computed for the GSA for MPGSA and obtained empirical cumulative distribution functions for accepted or rejected simulations (Figure 6b). Kolmogorov-Smirnov (K-S) tests between accepted and rejected samples indicated significant differences only for the hyperstim parameter for $\mathrm{Ca}^{2+}$ threshold. However, for Bax expression, we found significant differences for hyperstim as well as CREB [ $\max (\operatorname{Bax})>1 \mu \mathrm{M}$ : CaMKIV: K-S: 0.0247; P $=0.9991$; CREB: K-S: 0.4137; P < 0.0001; NMDAR: $P=0.9992, K-S: 0.0246$; hyperstim: $P<0.0001$; K-S: 0.7736; stim: $P>0.05$; K-S: 0.0193; $\max \left(\right.$ nuclear $\mathrm{Ca}^{2+}>10 \mu \mathrm{M}$ ): CaMKIV: $\mathrm{P}>0.05, \mathrm{~K}-\mathrm{S}$ : 0.0139; CREB: $\mathrm{P}>0.05, \mathrm{~K}-\mathrm{S}=0.0136$; NMDAR: $\mathrm{P}>$ $0.05, \mathrm{~K}-\mathrm{S}=0.0153$; hyperstim: $\mathrm{P}<0.0001, \mathrm{~K}-\mathrm{S}=1$; stim: $\mathrm{P}>0.05, \mathrm{~K}-\mathrm{S}=0.0104]$. Thus, MPGSA further confirms that $\mathrm{CREB}$ and excitotoxic glutamate pulses significantly affect Bax expression while solely excitotoxic glutamate pulses can affect $\mathrm{Ca}^{2+}$ influx.

\section{Effect of NMDAR activation and $\mathrm{Ca}^{2+} / \mathrm{CaM}$ signaling kinetics on $\mathrm{Ca}^{2+}$ influx and Bax expression}

Since activation of NMDAR and $\mathrm{Ca}^{2+} / \mathrm{CaM}$ signaling critically affects $\mathrm{Ca}^{2+}$ influx and activation of neuronal death pathways in neonatal hypoxic injury [35,36], we performed parameter scans by altering the reaction kinetics of NMDAR activation (Figure 7a-b). For NMDAR activation, our results showed that above $\mathrm{K}_{\mathrm{a}}=5 \mathrm{e}-4$, Bax expression significantly drops during PP2 administration, however, a drop in $\mathrm{Ca}^{2+}$ influx is delayed, but reaches significant reduction above $K_{a}=7 e-4$. This suggests that generally altering NMDAR activation only causes $\mathrm{Ca}^{2+}{ }^{2+}$-influx-Bax dissociation within a limited range. This is also indicative of a discontinuity in NMDAR signaling states that result in activation of cell death pathways. On the other hand, altering reaction kinetics of CaMKII activation results in a uniform relationship between $\mathrm{Ca}^{2+}$ influx and Bax expression during $\mathrm{Hx}$. However, for Ka values $\leq 9 \mathrm{e}-4$, we observe $\mathrm{Ca}^{2+}$-influx-Bax dissociation during PP2 administration.

\section{Effect of Src-NMDAR reaction kinetics and PP2-pre- treatment on $\mathrm{Ca}^{2+}$ influx and Bax expression}

Recent evidence strongly suggests that distinct modes of NMDAR signaling can dissociate channel $\mathrm{Ca}^{2+}$ influx and excitotoxic mechanisms in a Src-dependent manner $[12,13]$. Additionally, it is clinically relevant to understand the temporal dynamics of Src inhibition and its interaction with NMDARs, which can lead to an attenuation of excitotoxic mechanisms. We compared PP2-pretreatment simulations with simulations where PP2 administration following $\mathrm{Hx}$ was combined with alteration of Src activation of NMDARs (Figure 8). While pre-treatment clearly prevented significant $\mathrm{Ca}^{2+}$ influx or increased Bax expression, increasing $\mathrm{K}_{\mathrm{a}}$ of Src activation of NMDARs by just $20 \%\left(\mathrm{~K}_{\mathrm{a}}=0.012\right)$ resulted in a large drop in 
cytoplasmic $\mathrm{Ca}^{2+}$ and returned Bax expression levels almost similar to pre-treatment. This indicates that while PP2 administration that follows $\mathrm{Hx}$ may still be beneficial, the effect may be dramatically improved in combination with small molecules that specifically alter Src-NMDAR reaction kinetics.

\section{Discussion}

Drug design efforts are critically dependent on preclinical models of injury and disease. Often, these efforts are hampered by limitations of the animal models, and their relevance to human anatomy and physiology. The piglet model of neonatal brain injury is a uniquely relevant system, since the developmental trajectory of the porcine brain shares many similarities to the human brain[37], including development of a gyrencephalic neocortex. Importantly, injury induced by hypoxic insult affects the piglet brain in a manner similar to that seen in human neonatal brain tissue[38]. Thus, it is not surprising that a significant percentage of studies on neonatal brain injury employ the piglet model[39]. However, while few computational studies have used the piglet model to analyze the effect of neonatal brain injury on cerebral blood flow and metabolism[40-42], computational approaches to study intracellular signaling in normal and injured states has not been performed in this model. Since this approach has generated novel insights into neuronal function based on data from rodent models[43-45], our study represents a significant step in building computational models of intracellular signaling with greater translational relevance to human disease and injury conditions.

We have built a computational model of the $\mathrm{Ca}^{2+} / \mathrm{CaM}-\mathrm{Src}$-kinase signaling pathway in the context of neonatal brain injury induced by $\mathrm{Hx}$. The present computational analysis is primarily based on experimental data obtained from a translational large animal model of neonatal brain injury highlighting the clinical relevance of our model. Simulations from our model capture the molecular changes observed in $\mathrm{Hx}$, which we validated from previously published experimental work (Table 1, Figure 3). The present model also enables predictive analyses in determining the effect of pharmacological modulation of Src on different signaling components (Table 1). GSA (Figure 4) and MPGSA (Figure 5) of our model determined that differential interaction between input parameters results in dissociation of $\mathrm{Ca}^{2+}$ influx and Bax expression. Parameter scanning of reaction kinetics indicated that activation of NMDARs (Figure 6), and specifically Src activation kinetics of NMDARs (Figure 7) modulate dissociable signaling states between $\mathrm{Ca}^{2+}$ influx and Bax expression. Finally, simulations of our model strengthened the hypothesis that PP2 inhibition of Src kinase ameliorates the effect of neonatal brain injury, and that modulating SrcNMDAR reaction kinetics is a potential therapeutic strategy in attenuating the expression of apoptotic pathway proteins (Figure 7). Thus, our computational approach of modeling excitotoxic mechanisms in cortical neurons of the piglet model of neonatal brain injury provides a translational platform for designing and screening drugs targeting interactions between glutamate receptors and their functional modulators, such as Src kinase.

The dominant paradigm to explain excitotoxic neuronal damage involves an abnormal influx of $\mathrm{Ca}^{2+}$ via NMDARs and AMPA/kainate receptors. The large $\mathrm{Ca}^{2+}$ influx then activates multiple signaling cascades 
leading to dysfunctional mitochondrial metabolism and the formation of reactive oxygen species (ROS) [46]. Since hypoxic conditions limit ATP production, this further weakens neurons' ability to counter an excitotoxic event. In our model, a reduction in ATP production has been programmed as being triggered by a reduction in extracellular $\mathrm{O}_{2}$, in line with our previous work where ATP levels are used as a readout of tissue hypoxia[32]. Activation of ROS and other cell death and toxicity related pathways leads to the formation of proapoptotic proteins like $\mathrm{Bax}$ and $\mathrm{Bcl}-2$, which eventually leads to mitochondrial-dependent damage and nuclear DNA fragmentation. In our model we have focused on the proapoptotic protein Bax as a final readout of excitotoxic damage. However, $\mathrm{Ca}^{2+}$-mediated excitotoxic mechanisms can also lead to neuronal necrosis, which is a considerably faster form of cell death. It is likely that severe hypoxic conditions can lead to both necrosis and apoptosis. Evidence also suggests that in models of neonatal brain injury, hypoxia may induce both these forms of cell death on a continuum, rather than completely discrete events without any overlap[2]. Although apoptosis is a slower form of neuronal death, the molecular processes that eventually lead to death are well underway within minutes of hypoxic/ischemic insults[47, 48], and Bax translocation to mitochondria also occurs on a relatively rapid timescale[49]. Thus, although the timescale of Bax expression in our model is relatively fast, there is precedent for a comparable timescale from previously published work.

Excitotoxic mechanisms have been studied in the context of hypoxic brain injury for a considerable period of time. However, few if any effective pharmacological agents that attenuate neuronal damage induced by excessive glutamatergic excitation have been identified. Our previous work strongly indicates that the Src kinase inhibitor PP2 is an effective intervention to reduce Hx-induced excitotoxic neuronal damage in the piglet neocortex $[19,50]$. Our previous work also suggests that this neuronal damage is initially triggered by the activation of the $\mathrm{Ca}^{2+} / \mathrm{CaM}$ pathway that cascades through a series of intermediate steps, including the activation of CaMKII, CaMKK2, nuclear CaMKIV, and finally CREB. However, the GSA and the MPGSA of our computational model suggest that, although excitotoxic hyperstimulation shows significant interaction with key signaling members of this cascade, the only other critical component that significantly interacts with excitotoxic hyperstimulation is CREB. This indicates that CaMKIV, while important, may not be a limiting component of excitotoxic mechanisms that signal via Src kinase. Another important insight from the GSA and the MPGSA points to the existence of different and discrete signaling states, where $\mathrm{Ca}^{2+}$ influx and Bax expression can be dissociated during Src inhibition. This is in line with emergent evidence on metabotropic-like signaling of NMDARs triggered by excitotoxic stimuli, wherein cell death can be dissociated from $\mathrm{Ca}^{2+}$ influx per se [12, 13]. Interestingly, since Src kinase interaction with NMDARs during excitotoxic damage is mediated by Panx 1 channels [13], it would be useful in future studies to also include Panx1 as part of the intracellular signaling mechanism in our model.

An important contribution of our work is the establishment of a computational platform to analyze pharmacokinetics and pharmacodynamics of drugs targeted to reducing neuronal damage induced by hypoxic excitotoxic mechanisms. In our study, the Src inhibitor PP2 served to define the role of Src kinase in the pathway. However, a key difference between our previous studies and our current model

Page $12 / 28$ 
simulations is that in previous studies comparison between groups included PP2 pre-treated piglets exposed to $\mathrm{Hx}$, whereas in our model PP2 was administered 2 minutes after $\mathrm{Hx}$. In spite of this difference, the model gave us an opportunity to compare pre-treatment with PP2 against post-Hx administration. Although altering CaMKII activation results in modest reduction in $\mathrm{Ca}^{2+}$ influx but does not significantly alter a drop in Bax expression, modulating Src activation of NMDARs in addition to PP2 administration caused a significant reduction in both $\mathrm{Ca}^{2+}$ influx as well as Bax expression (Figure 7). Thus, our model indicates that designing or screening small molecules that effectively mimic the activation of NMDARs by Src kinase could be a potential therapeutic strategy in mitigating excitotoxic neuronal damage.

\section{Study Limitations}

Our study, although addressing the important problem of excitotoxic mechanisms in cortical neurons of the piglet model of neonatal brain injury, has some limitations. For the purpose of the computational analysis, we designed our model to specifically address excitotoxic $\mathrm{Ca}^{2+}$ influx via NMDARs. Although our model does include other sources of $\mathrm{Ca}^{2+}$ influx into the cytoplasm and nucleus, including CP-AMPARs, VGCCs, and the ER, we have not included detailed regulatory pathways and mechanisms for these sources, which minimized their contribution to the overall dynamics of $\mathrm{Ca}^{2+}$ influx. Although sources such as VGCCs may play a minor role in neuronal injury when compared to NMDARs [51], a more detailed model including other $\mathrm{Ca}^{2+}$ sources may enable testing competing hypotheses regarding the role of $\mathrm{Ca}^{2+}$ in excitotoxicity, such as the "Ca ${ }^{2+}$-loading" hypothesis [52] and the "source specificity" hypothesis[53].

In the present study, we have not included a detailed model of mitochondrial metabolism and how changes in extracellular $\mathrm{O}_{2}$ during $\mathrm{Hx}$ may affect these dynamics and feedback onto the Src kinase pathway. In addition, we have not included a mitochondrial $\mathrm{Ca}^{2+}$ buffering mechanism, which is likely altered in conditions that lead to neuronal death [54-56], although these mechanisms are downstream of our final readout of Bax expression.

Importantly, our model input is a physiologically very slow rate of glutamate release and so captures slower components of excitotoxic release. It would be helpful to use faster glutamate release dynamics in future studies and adjust other temporal kinetics of the model accordingly.

Finally, in our analysis, we did not include a comprehensive sub-model of apoptosis. Future studies should also include the expression of the pro-apoptotic protein Bad as well as anti-apoptotic proteins, such as Bcl-2 and Bcl-xl, for which experimental data is available in the piglet model of neonatal brain injury[57].

\section{Conclusions}

We have used experimental and computational approaches to determine the significance of the Src$\mathrm{Ca}^{2+} / \mathrm{CaM}$ pathway in neuronal excitotoxicity in a large animal model of neonatal hypoxic brain injury. Our computational model was validated with experimental measurements of critical intracellular 
signaling components and captures key molecular trends in this pathway. Our computational model indicates that pharmacological inhibition of Src kinase leads to signaling states wherein $\mathrm{Ca} 2+$ influx and the onset of Bax expression are dissociable. Finally, our computational model predicts that small molecules that specifically modulate the interaction between the NMDA receptor and Src can significantly contribute to a reduction in Bax expression. Our study combines experimental and computational methods to provide a translational platform to investigate key signaling cascades triggered by neonatal hypoxic brain injury in neurons.

\section{Declarations}

\section{Ethical approval and consent to participate}

This study uses animal tissue (piglet). All experimental methods using animals were performed in accordance with the relevant guidelines and regulations. Appropriate use of drugs in standardized dosage was followed during experiments to reduce or eliminate pain, according to the NIH Guidelines for the Care and Use of Laboratory Animals[27]. The experimental protocol was approved by the Institutional Animal Care and Use Committee of Drexel University (IACUC protocol \#200491).

\section{Consent for publication}

Not applicable.

\section{Availability of data and materials}

Model file has been added in supplementary material. Model files and manuscript data will be uploaded to the public repository Zenodo.org following manuscript acceptance.

\section{Competing interests}

The authors declare that they have no competing interests.

\section{Funding}

Funded by NICHD-20337 (PI: MDP), R37NS109478 (PI: VG), R21NS119344 (PI: VG) and District of Columbia Intellectual and Developmental Disabilities Research Center U54HD090257 (PI: VG), K12HD001399 (NIH/NICHD) Child Health Research Career Development Award (CHRCDA) (PI:PK) Children's National Board of Visitors Grant (PI: PK), 5K12HD001399-20 (NIH/NICHD) Child Health Research Career Development Award (CHRCDA) (PI:IK).

\section{Authors' contributions}

PK and AS conceptualized the study. PK collected experimental data, with help from IK. AV, RV, and AS designed, validated, and optimized the computational model. VG provided salary support. MDP 
supervised the experimental aspect of the study. AS and PK supervised the computational aspect of the study. AS and PK wrote the manuscript with contribution from AV, RV, IK, and VG.

\section{Acknowledgements}

We acknowledge and dedicate this manuscript to Dr. Maria Delivoria-Papadopoulos, in who's laboratory and under who's supervision the experimental data for this manuscript was collected. Dr. DelivoriaPapadopoulos was a brilliant scientist, a mentor and a friend who inspired many generations of physicians and scientists to pursue research in neonatal brain injury.

\section{Authors' information}

Not applicable.

\section{References}

1. Burd I, Welling J, Kannan G, Johnston M v. Excitotoxicity as a Common Mechanism for Fetal Neuronal Injury with Hypoxia and Intrauterine Inflammation. Advances in Pharmacology. Academic Press; 2016;76:85-101.

2. Northington FJ, Chavez-Valdez R, Martin LJ. Neuronal cell death in neonatal hypoxia-ischemia. Annals of Neurology [Internet]. John Wiley \& Sons, Ltd; 2011 [cited 2021 Oct 3];69:743-58. Available from: https://onlinelibrary.wiley.com/doi/full/10.1002/ana.22419

3. Lawn JE, Cousens S, Zupan J. 4 million neonatal deaths: When? Where? Why? The Lancet [Internet]. Elsevier; 2005 [cited 2021 Oct 20];365:891-900. Available from: http://www.thelancet.com/article/S0140673605710485/fulltext

4. Rossi DJ, Oshima T, Attwell D. Glutamate release in severe brain ischaemia is mainly by reversed uptake. Nature 2000 403:6767 [Internet]. Nature Publishing Group; 2000 [cited 2021 Oct 3];403:31621. Available from: https://www.nature.com/articles/35002090

5. Abdel-Hamid KM, Tymianski M. Mechanisms and Effects of Intracellular Calcium Buffering on Neuronal Survival in Organotypic Hippocampal Cultures Exposed to Anoxia/Aglycemia or to Excitotoxins. Journal of Neuroscience [Internet]. Society for Neuroscience; 1997 [cited 2021 Oct 3];17:3538-53. Available from: https://www.jneurosci.org/content/17/10/3538

6. Timofeeva Y, Volynski K. Calmodulin as a major calcium buffer shaping vesicular release and shortterm synaptic plasticity: facilitation through buffer dislocation. Frontiers in Cellular Neuroscience. Frontiers; 2015;0:239.

7. Clapham DE. Calcium Signaling. Cell. Cell Press; 2007;131:1047-58.

8. Thornton C, Leaw B, Mallard C, Nair S, Jinnai M, Hagberg H. Cell Death in the Developing Brain after Hypoxia-Ischemia. Frontiers in Cellular Neuroscience. Frontiers; 2017;0:248.

9. Choi DW. Excitotoxicity: Still Hammering the Ischemic Brain in 2020. Frontiers in Neuroscience. Frontiers; 2020;0:1104. 
10. Kalia L v., Kalia SK, Salter MW. NMDA receptors in clinical neurology: excitatory times ahead. The Lancet Neurology. Elsevier; 2008;7:742-55.

11. Muir KW. Glutamate-based therapeutic approaches: clinical trials with NMDA antagonists. Current Opinion in Pharmacology. Elsevier; 2006;6:53-60.

12. Rajani V, Sengar AS, Salter MW. Tripartite signalling by NMDA receptors. Molecular Brain 2020 13:1 [Internet]. BioMed Central; 2020 [cited 2021 Oct 3];13:1-7. Available from:

https://molecularbrain.biomedcentral.com/articles/10.1186/s13041-020-0563-z

13. Weilinger NL, Lohman AW, Rakai BD, Ma EMM, Bialecki J, Maslieieva V, et al. Metabotropic NMDA receptor signaling couples Src family kinases to pannexin-1 during excitotoxicity. Nature Neuroscience 2016 19:3 [Internet]. Nature Publishing Group; 2016 [cited 2021 Oct 3];19:432-42. Available from: https://www.nature.com/articles/nn.4236

14. Ohnishi H, Murata Y, Okazawa H, Matozaki T. Src family kinases: modulators of neurotransmitter receptor function and behavior. Trends in Neurosciences. 2011;34:629-37.

15. Mishra OP, Delivoria-Papadopoulos M. Nitric oxide-mediated Ca++-influx in neuronal nuclei and cortical synaptosomes of normoxic and hypoxic newborn piglets. Neuroscience Letters. Elsevier; 2002;318:93-7.

16. Delivoria-Papadopoulos M, Ashraf QM, Mishra OP. Brain tissue energy dependence of CaM kinase IV cascade activation during hypoxia in the cerebral cortex of newborn piglets. Neuroscience Letters. 2011;491:113-7.

17. Delivoria-Papadopoulos M, Ashraf QM, Mishra OP. Effect of Hypoxia on Expression of Apoptotic Proteins in Nuclear, Mitochondrial and Cytosolic Fractions of the Cerebral Cortex of Newborn Piglets: The Role of Nuclear Ca++-influx. Neurochemical Research 2008 33:7 [Internet]. Springer; 2008 [cited 2021 Oct 20];33:1196-204. Available from: https://link.springer.com/article/10.1007/s11064-0079568-6

18. Bading $\mathrm{H}$. Nuclear calcium signalling in the regulation of brain function. Nature Reviews Neuroscience 2013 14:9 [Internet]. Nature Publishing Group; 2013 [cited 2021 Oct 3];14:593-608. Available from: https://www.nature.com/articles/nrn3531

19. Delivoria-Papadopoulos M, Ashraf QM, Mishra OP. Mechanism of CaM kinase IV activation during hypoxia in neuronal nuclei of the cerebral cortex of newborn piglets: The role of Src kinase. Neurochemical Research. 2011;36:1512-9.

20. Brenes A, Afzal V, Kent R, Lamond Al. The Encyclopedia of Proteome Dynamics: a big data ecosystem for (prote)omics. Nucleic Acids Research [Internet]. Oxford Academic; 2018 [cited 2021 Oct 20];46:D1202-9. Available from: https://academic.oup.com/nar/article/46/D1/D1202/4107223

21. Wiśniewski JR, Hein MY, Cox J, Mann M. A “Proteomic Ruler” for Protein Copy Number and Concentration Estimation without Spike-in Standards. Molecular \& Cellular Proteomics. Elsevier; 2014;13:3497-506.

22. Tuckerman JR, Zhao Y, Hewitson KS, Tian YM, Pugh CW, Ratcliffe PJ, et al. Determination and comparison of specific activity of the HIF-prolyl hydroxylases. FEBS Letters. No longer published by 
Elsevier; 2004;576:145-50.

23. Global Sensitivity Analysis for SimBiology - File Exchange - MATLAB Central [Internet]. [cited 2021 Oct 7]. Available from: https://www.mathworks.com/matlabcentral/fileexchange/74955-globalsensitivity-analysis-for-simbiology

24. Tiemann CA, Vanlier J, Oosterveer MH, Groen AK, Hilbers PAJ, van Riel NAW. Parameter Trajectory Analysis to Identify Treatment Effects of Pharmacological Interventions. PLoS Computational Biology. 2013;9.

25. Saltelli A, Annoni P, Azzini I, Campolongo F, Ratto M, Tarantola S. Variance based sensitivity analysis of model output. Design and estimator for the total sensitivity index. Computer Physics Communications. 2010;181:259-70.

26. Kilkenny C, Browne WJ, Cuthill IC, Emerson M, Altman DG. Improving Bioscience Research Reporting: The ARRIVE Guidelines for Reporting Animal Research. PLOS Biology [Internet]. Public Library of Science; 2010 [cited 2021 Oct 20];8:e1000412. Available from:

https://journals.plos.org/plosbiology/article?id=10.1371/journal.pbio.1000412

27. NIH, OD, OER, OLAW. GUIDE LABORATORY ANIMALS FOR THE CARE AND USE OF Eighth Edition Committee for the Update of the Guide for the Care and Use of Laboratory Animals Institute for Laboratory Animal Research Division on Earth and Life Studies. 2011 [cited 2021 Oct 7]; Available from: http://www.nap.edu.

28. Zolman JF. Biostatistics: experimental design and statistical inference. Oxford University Press; 1993;343.

29. Giuffrida AM, Cox D, Mathias AP. RNA POLYMERASE ACTIVITY IN VARIOUS CLASSES OF NUCLEI FROM DIFFERENT REGIONS OF RAT BRAIN DURING POSTNATAL DEVELOPMENT. Journal of Neurochemistry [Internet]. John Wiley \& Sons, Ltd; 1975 [cited 2021 Oct 7];24:749-55. Available from: https://onlinelibrary.wiley.com/doi/full/10.1111/j.1471-4159.1975.tb03859.x

30. LOWRY OH, ROSEBROUGH NJ, FARR AL, RANDALL RJ. PROTEIN MEASUREMENT WITH THE FOLIN PHENOL REAGENT. Journal of Biological Chemistry. Elsevier; 1951;193:265-75.

31. Lamprecht W, Stein P, Heinz F, analysis HW-M of enzymatic, 1974 undefined. Creatine phosphate. Elsevier [Internet]. [cited 2021 Oct 7]; Available from:

https://www.sciencedirect.com/science/article/pii/B9780120913046500288

32. Delivoria-Papadopoulos M, Ashraf QM, Mishra OP. Brain tissue energy dependence of CaM kinase IV cascade activation during hypoxia in the cerebral cortex of newborn piglets. Neuroscience Letters. Elsevier; 2011;491:113-7.

33. Deisseroth K, Mermelstein PG, Xia H, Tsien RW. Signaling from synapse to nucleus: the logic behind the mechanisms This review comes from a themed issue on Signalling mechanisms Edited by Morgan Sheng and Terrance P Snutch. Current Opinion in Neurobiology [Internet]. 2003 [cited 2021 Oct 20];13:1-12. Available from: www.current-opinion.com

34. Mishra OP, Zubrow AB, Ashraf QM, Delivoria-Papadopoulos M. Nuclear Ca++-influx, $\mathrm{Ca++/Calmodulin-Dependent} \mathrm{Protein} \mathrm{Kinase} \mathrm{IV} \mathrm{Activity} \mathrm{and} \mathrm{CREB} \mathrm{Protein} \mathrm{Phosphorylation} \mathrm{during}$ 
Post-Hypoxic Reoxygenation in Neuronal Nuclei of Newborn Piglets: The Role of Nitric Oxide. Neurochemical Research 2006 31:12 [Internet]. Springer; 2006 [cited 2021 Oct 20];31:1463-71. Available from: https://link.springer.com/article/10.1007/s11064-006-9204-x

35. Elsayed NA, Boyer TM, Burd I. Fetal Neuroprotective Strategies: Therapeutic Agents and Their Underlying Synaptic Pathways. Frontiers in Synaptic Neuroscience. Frontiers; 2021;0:33.

36. Turlova E, Wong R, Xu B, Li F, Du L, Habbous S, et al. TRPM7 Mediates Neuronal Cell Death Upstream of Calcium/Calmodulin-Dependent Protein Kinase II and Calcineurin Mechanism in Neonatal Hypoxic-Ischemic Brain Injury. Translational Stroke Research 2020 12:1 [Internet]. Springer; 2020 [cited 2021 Oct 20];12:164-84. Available from: https://link.springer.com/article/10.1007/s12975020-00810-3

37. Conrad MS, Dilger RN, Johnson RW. Brain Growth of the Domestic Pig (Sus scrofa) from 2 to 24 Weeks of Age: A Longitudinal MRI Study. Developmental Neuroscience [Internet]. Karger Publishers; 2012 [cited 2021 Oct 20];34:291-8. Available from: https://www.karger.com/Article/FullText/339311

38. Morton PD, Korotcova L, Lewis BK, Bhuvanendran S, Ramachandra SD, Zurakowski D, et al. Abnormal neurogenesis and cortical growth in congenital heart disease. Science Translational Medicine [Internet]. American Association for the Advancement of Science; 2017 [cited 2021 Oct 20];9. Available from: https://www.science.org/doi/abs/10.1126/scitranslmed.aah7029

39. Roohey T, Raju TNK, Moustogiannis AN. Animal models for the study of perinatal hypoxic-ischemic encephalopathy: a critical analysis. Early Human Development. Elsevier; 1997;47:115-46.

40. Moroz T, Banaji M, Robertson NJ, Cooper CE, Tachtsidis I. Computational modelling of the piglet brain to simulate near-infrared spectroscopy and magnetic resonance spectroscopy data collected during oxygen deprivation. Journal of the Royal Society Interface [Internet]. The Royal Society; 2012 [cited 2021 Oct 10];9:1499. Available from: /pmc/articles/PMC3367814/

41. Caldwell M, Moroz T, Hapuarachchi T, Bainbridge A, Robertson NJ, Cooper CE, et al. Modelling Blood Flow and Metabolism in the Preclinical Neonatal Brain during and Following Hypoxic-lschaemia. PLOS ONE [Internet]. Public Library of Science; 2015 [cited 2021 Oct 10];10:e0140171. Available from: https://journals.plos.org/plosone/article?id=10.1371/journal.pone.0140171

42. Moroz T, Hapuarachchi T, Bainbridge A, Price D, Cady E, Baer E, et al. Modelling Blood Flow and Metabolism in the Piglet Brain During Hypoxia-Ischaemia: Simulating Brain Energetics. Advances in Experimental Medicine and Biology [Internet]. Springer; 2013 [cited 2021 Oct 10];789:339. Available from: /pmc/articles/PMC4037999/

43. Bhalla US, lyengar R. Emergent properties of networks of biological signaling pathways. Science. 1999;283:381-7.

44. Mäki-Marttunen T, lannella N, Edwards AG, Einevoll GT, Blackwell KT. A unified computational model for cortical post-synaptic plasticity. eLife. eLife Sciences Publications Ltd; 2020;9:1-42.

45. Blackwell KT, Salinas AG, Tewatia P, English B, Kotaleski JH, Lovinger DM. Molecular mechanisms underlying striatal synaptic plasticity: relevance to chronic alcohol consumption and seeking. 
European Journal of Neuroscience [Internet]. John Wiley \& Sons, Ltd; 2019 [cited 2021 Oct 20];49:768-83. Available from: https://onlinelibrary.wiley.com/doi/full/10.1111/ejn.13919

46. Mattson MP. Excitotoxicity. Stress: Physiology, Biochemistry, and Pathology Handbook of Stress Series, Volume 3. Elsevier; 2019;125-34.

47. Lipton P. Ischemic Cell Death in Brain Neurons. https://doi.org/101152/physrev19997941431 [Internet]. American Physiological SocietyBethesda, MD; 1999 [cited 2021 Oct 10];79:1431-568. Available from: https://journals.physiology.org/doi/abs/10.1152/physrev.1999.79.4.1431

48. Andou Y, Mitani A, Masuda S, Arai T, Kataoka K. Re-evaluation of ischemia-induced neuronal damage in hippocampal regions in the normothermic gerbil. Acta Neuropathologica 1992 85:1 [Internet]. Springer; 1992 [cited 2021 Oct 20];85:10-4. Available from: https://link.springer.com/article/10.1007/BF00304628

49. Lok J, Martin LJ. Rapid Subcellular Redistribution of Bax Precedes Caspase-3 and Endonuclease Activation during Excitotoxic Neuronal Apoptosis in Rat Brain. https://home.liebertpub.com/neu [Internet]. Mary Ann Liebert, Inc.; 2004 [cited 2021 Oct 10];19:815-28. Available from: https://www.liebertpub.com/doi/abs/10.1089/08977150260190410

50. Angelis D, Delivoria-Papadopoulos M. Effects of Src kinase inhibition on expression of protein tyrosine phosphatase 1B after brain hypoxia in a piglet animal model. Mediators of Inflammation. Hindawi Limited; 2017;2017.

51. Stanika RI, Villanueva I, Kazanina G, Andrews SB, Pivovarova NB. Comparative Impact of VoltageGated Calcium Channels and NMDA Receptors on Mitochondria-Mediated Neuronal Injury. Journal of Neuroscience [Internet]. Society for Neuroscience; 2012 [cited 2021 Oct 10];32:6642-50. Available from: https://www.jneurosci.org/content/32/19/6642

52. Hartley D, Kurth M, Bjerkness L, Weiss J, Choi D. Glutamate receptor-induced $45 \mathrm{Ca} 2+$ accumulation in cortical cell culture correlates with subsequent neuronal degeneration. Journal of Neuroscience [Internet]. Society for Neuroscience; 1993 [cited 2021 Oct 11];13:1993-2000. Available from: https://www.jneurosci.org/content/13/5/1993

53. Tymianski M, Charlton $M$, Carlen $P$, Tator $C$. Source specificity of early calcium neurotoxicity in cultured embryonic spinal neurons. Journal of Neuroscience [Internet]. Society for Neuroscience; 1993 [cited 2021 Oct 11];13:2085-104. Available from: https://www.jneurosci.org/content/13/5/2085

54. Calvo-Rodriguez M, Hou SS, Snyder AC, Kharitonova EK, Russ AN, Das S, et al. Increased mitochondrial calcium levels associated with neuronal death in a mouse model of Alzheimer's disease. Nature Communications 2020 11:1 [Internet]. Nature Publishing Group; 2020 [cited 2021 Oct 11];11:1-17. Available from: https://www.nature.com/articles/s41467-020-16074-2

55. Ranjan B, Chong KH, Zheng J. Composite mathematical modeling of calcium signaling behind neuronal cell death in Alzheimer's disease. BMC Systems Biology 2018 12:1 [Internet]. BioMed Central; 2018 [cited 2021 Oct 11];12:61-74. Available from: https://bmcsystbiol.biomedcentral.com/articles/10.1186/s12918-018-0529-2 
56. Luetjens CM, Bui NT, Sengpiel B, Münstermann G, Poppe M, Krohn AJ, et al. Delayed Mitochondrial Dysfunction in Excitotoxic Neuron Death: Cytochrome c Release and a Secondary Increase in Superoxide Production. Journal of Neuroscience [Internet]. Society for Neuroscience; 2000 [cited 2021 Oct 11];20:5715-23. Available from: https://www.jneurosci.org/content/20/15/5715

57. Delivoria-Papadopoulos M, Ashraf QM, Mishra OP. Effect of Hypoxia on Expression of Apoptotic Proteins in Nuclear, Mitochondrial and Cytosolic Fractions of the Cerebral Cortex of Newborn Piglets: The Role of Nuclear Ca++-influx. Neurochemical Research 2008 33:7 [Internet]. Springer; 2008 [cited 2021 Oct 20];33:1196-204. Available from: https://link.springer.com/article/10.1007/s11064-0079568-6

\section{Tables}

Table 1. Model validation and predictive analysis. Validation was performed on a dataset obtained from Delivoria-Papadopoulos et al., 2011 and our current work. Specifically, the effect of PP2 was used for validative analysis. The percentage change from $\mathrm{Hx}$ to $\mathrm{Hx}+\mathrm{PP} 2$ conditions were calculated and compared between experimental and simulation data. Experimental trends were qualitatively assessed as match or mismatch. Effect accuracy was calculated based on comparison between PP2 effects as seen in experimental and simulation data. Depending on model prediction compared to experimental data, effects were labeled as either an 'overstimate' or 'underestimate'. 


\begin{tabular}{|c|c|c|c|c|c|c|}
\hline \multicolumn{7}{|c|}{ Validation analyses } \\
\hline \multirow{3}{*}{ Molecule } & \multicolumn{2}{|c|}{ Experimental data } & \multicolumn{2}{|c|}{ Simulation data } & \multirow{3}{*}{$\begin{array}{c}\text { Trend } \\
\text { match/mismatch }\end{array}$} & \multirow{3}{*}{$\begin{array}{c}\text { Accuracy (Effect of } \\
\text { PP2) }\end{array}$} \\
\hline & \multicolumn{2}{|c|}{$\begin{array}{c}\mathrm{Hx} \text { to } \mathrm{Hx}+\mathrm{PP} 2 \\
\text { (\% change w.r.t } \\
\mathrm{Hx} \text { ) }\end{array}$} & \multicolumn{2}{|c|}{$\begin{array}{c}\mathrm{Hx} \text { to } \mathrm{Hx}+\mathrm{PP} 2 \\
\text { (\% change w.r.t } \\
\mathrm{Hx})\end{array}$} & & \\
\hline & change & trend & change & trend & & \\
\hline Nuclear $\mathrm{Ca}^{2+}$ & -28.07 & $\boldsymbol{\nabla}$ & -44.85 & $\boldsymbol{\nabla}$ & Match & $40.22 \%$; overestimate \\
\hline $\begin{array}{l}\text { Activated } \\
\mathrm{Ca}^{2+} / \mathrm{CaM}\end{array}$ & -63.22 & $\boldsymbol{\nabla}$ & -43.63 & $\boldsymbol{\nabla}$ & Match & $\begin{array}{l}69.01 \% ; \\
\text { underestimate }\end{array}$ \\
\hline $\begin{array}{l}\text { Activated } \\
\text { CaMKIV }\end{array}$ & -59.10 & $\boldsymbol{\nabla}$ & -65.27 & $\boldsymbol{\nabla}$ & Match & $89.56 \%$; overestimate \\
\hline Activated CREB & -36.84 & $\boldsymbol{\nabla}$ & -91.20 & $\boldsymbol{\nabla}$ & Match & $47.56 \%$; overestimate \\
\hline \multicolumn{7}{|c|}{ Predictive analysis (test validation) } \\
\hline \multirow{3}{*}{ Molecule } & \multicolumn{2}{|c|}{ Experimental data } & \multicolumn{2}{|c|}{ Simulation data } & \multirow{3}{*}{$\begin{array}{c}\text { Trend } \\
\text { match/mismatch }\end{array}$} & \multirow{3}{*}{$\begin{array}{c}\text { Accuracy (Effect of } \\
\text { PP2) }\end{array}$} \\
\hline & \multicolumn{2}{|c|}{$\begin{array}{c}\mathrm{Hx} \text { to } \mathrm{Hx}+\mathrm{PP} 2 \\
\text { (\% change w.r.t } \\
\mathrm{Hx} \text { ) }\end{array}$} & \multicolumn{2}{|c|}{$\begin{array}{c}\mathrm{Hx} \text { to } \mathrm{Hx}+\mathrm{PP} 2 \\
\text { (\% change w.r.t } \\
\mathrm{Hx} \text { ) }\end{array}$} & & \\
\hline & change & trend & change & trend & & \\
\hline $\begin{array}{l}\text { Activated } \\
\text { CaMKK(2) }\end{array}$ & -42.81 & $\boldsymbol{\nabla}$ & -42.38 & $\boldsymbol{\nabla}$ & Match & $99.0 \%$; underestimate \\
\hline
\end{tabular}

\section{Figures}




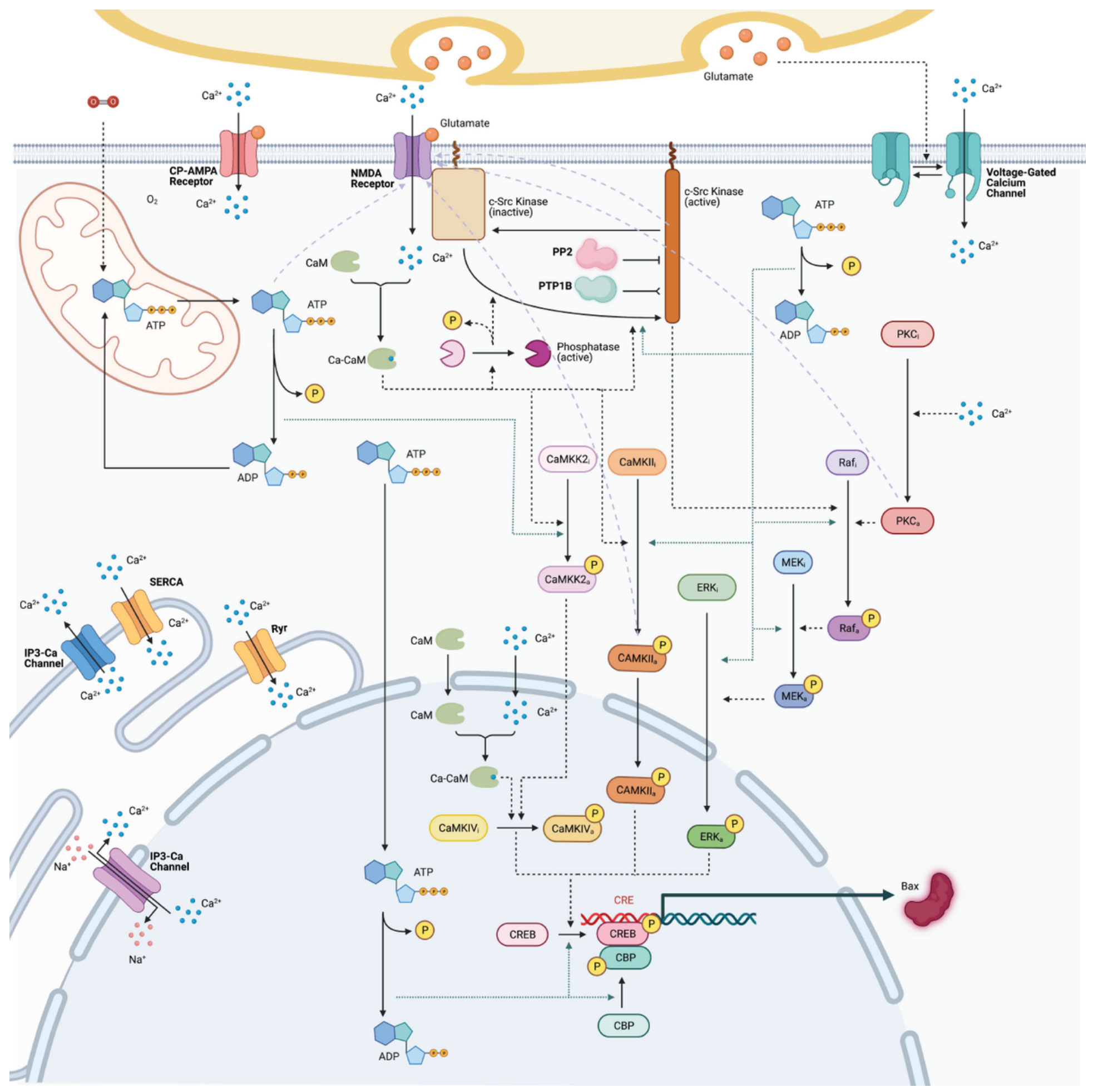

Figure 1

Representative visualization of $\mathrm{Ca} 2+/ \mathrm{CaM}-S r c$ kinase intracellular signaling computational model. Cartoon depiction of the interactions captured in our SimBiology model of excitotoxic glutamate pulses and subsequent activation of NMDARs and $\mathrm{Ca} 2+/ \mathrm{CaM}$ signaling through $\mathrm{Src}$ kinase and the eventual transcription of the pro-apoptotic protein Bax. Figure created with BioRender. 
a

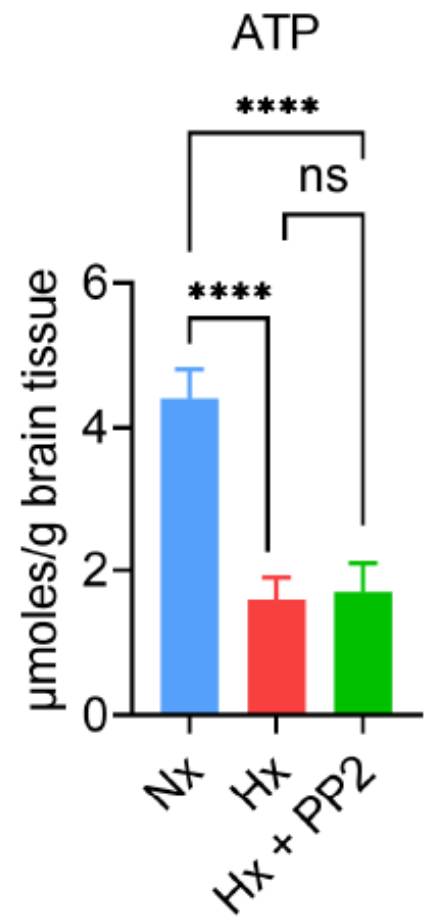

C

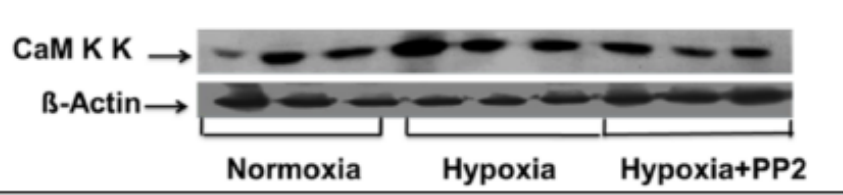

b

\author{
Nuclear $\mathrm{Ca}^{+}$
}

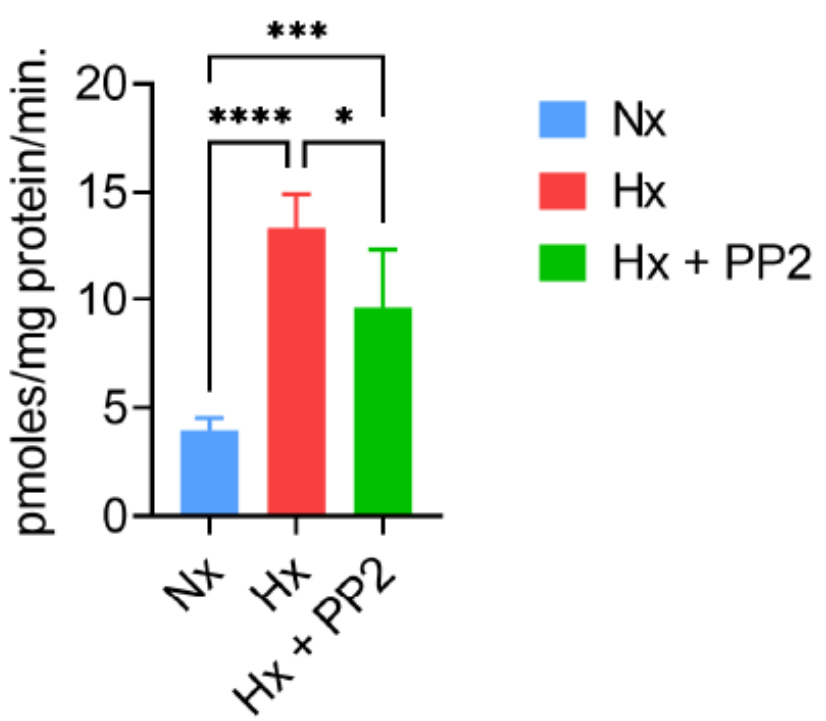

cytosolic CaMKK

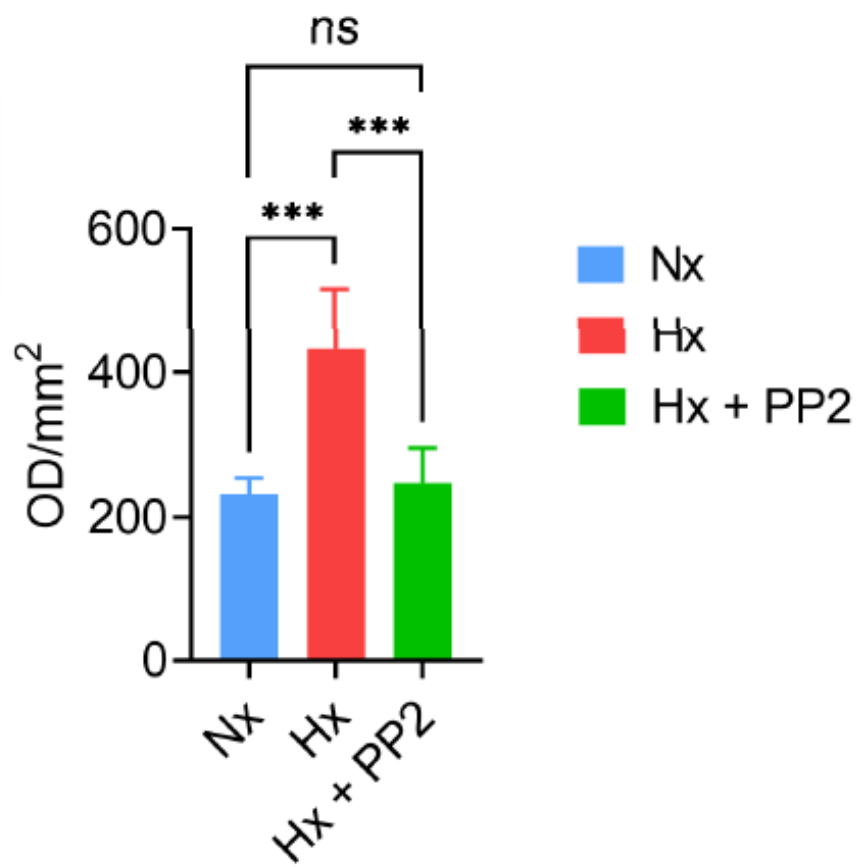

Figure 2

Experimental analysis of biochemical correlates and CaMKK2 expression in the piglet model of neonatal hypoxic brain injury. a. ATP measurement in cerebral cortex tissue from piglets in the $\mathrm{Nx}$ (blue), $\mathrm{Hx}$ (red) and Hx + PP2 (green) groups; Statistics: One-way ANOVA overall: $F(2,10)=89.02(P<0.0001)$, Tukey multiple comparison test: $\mathrm{Nx}$ vs. $\mathrm{Hx}: \mathrm{P}<0.0001, \mathrm{Hx}$ vs. $\mathrm{Hx}+\mathrm{PP} 2: \mathrm{P}=0.9253, \mathrm{Nx}$ vs. $\mathrm{Hx}+\mathrm{PP2}: \mathrm{P}<0.0001$ b. Nuclear Ca2+ influx in cerebral cortical tissue for all groups; Statistics: One-way ANOVA overall: $\mathrm{F}(2$, 
$14)=32.94(\mathrm{P}<0.0001)$, Tukey multiple comparison test: $\mathrm{Nx}$ vs. $\mathrm{Hx}: \mathrm{P}<0.0001, \mathrm{Hx}$ vs. $\mathrm{Hx}+\mathrm{PP2}: \mathrm{P}=$ 0.0116, Nx vs. Hx + PP2: P = 0.0007 c. Western blots of CaMKK2 for Nx, Hx, and Hx + PP2 groups, control: $\beta$-actin d. Quantification of CaMKK2 protein expression from western blots; Statistics: One-way ANOVA overall: $F(2,15)=19.68(P<0.0001)$, Tukey multiple comparison test: $\mathrm{Nx}$ vs. $\mathrm{Hx}: \mathrm{P}=0.0004, \mathrm{Hx}$ vs. $\mathrm{Hx}+$ $P P 2: P=0.0002, N x$ vs. $H x+P P 2: P=0.9336$.

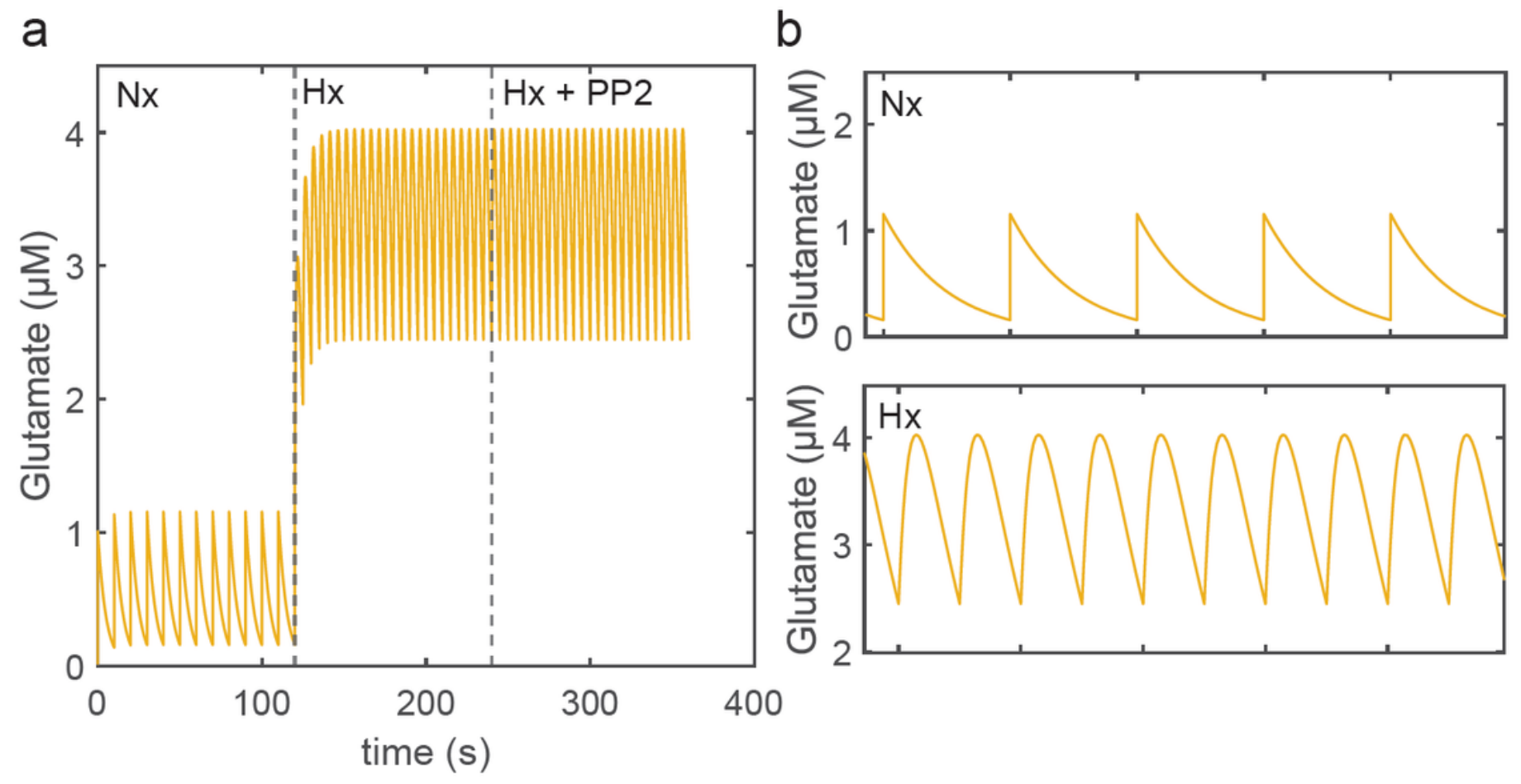

Figure 3

Model input. a. Glutamate pulses during the three stages of the simulation - normoxia (Nx), hypoxia ( $\mathrm{Hx})$, and $\mathrm{Hx}+\mathrm{PP} 2 \mathrm{~b}$. Amplified view of Nx glutamate stimulation and c. amplified view of $\mathrm{Hx}$ and $\mathrm{Hx}+\mathrm{PP} 2$ 
a

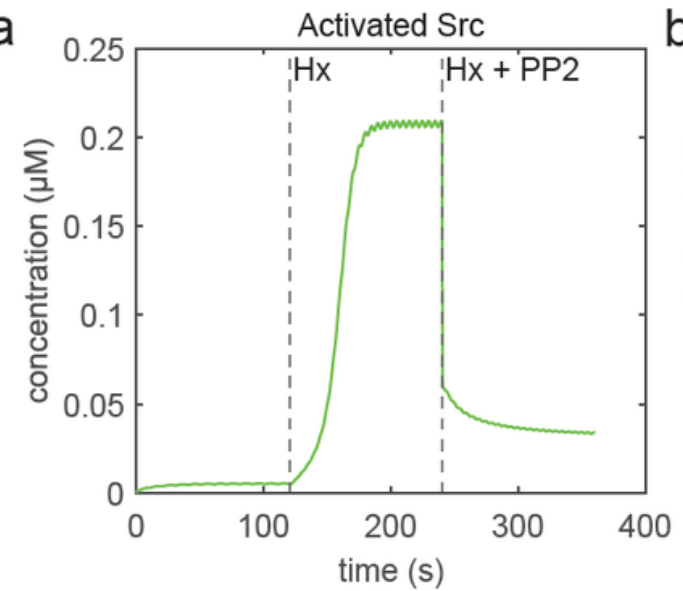

$$
\text { b }
$$

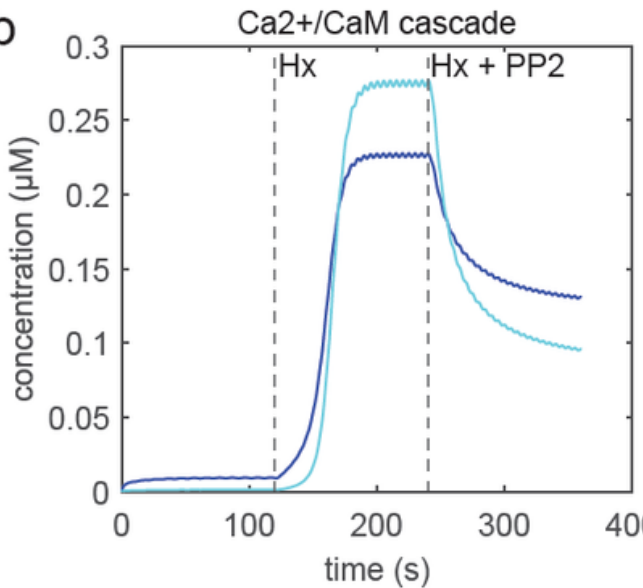

C
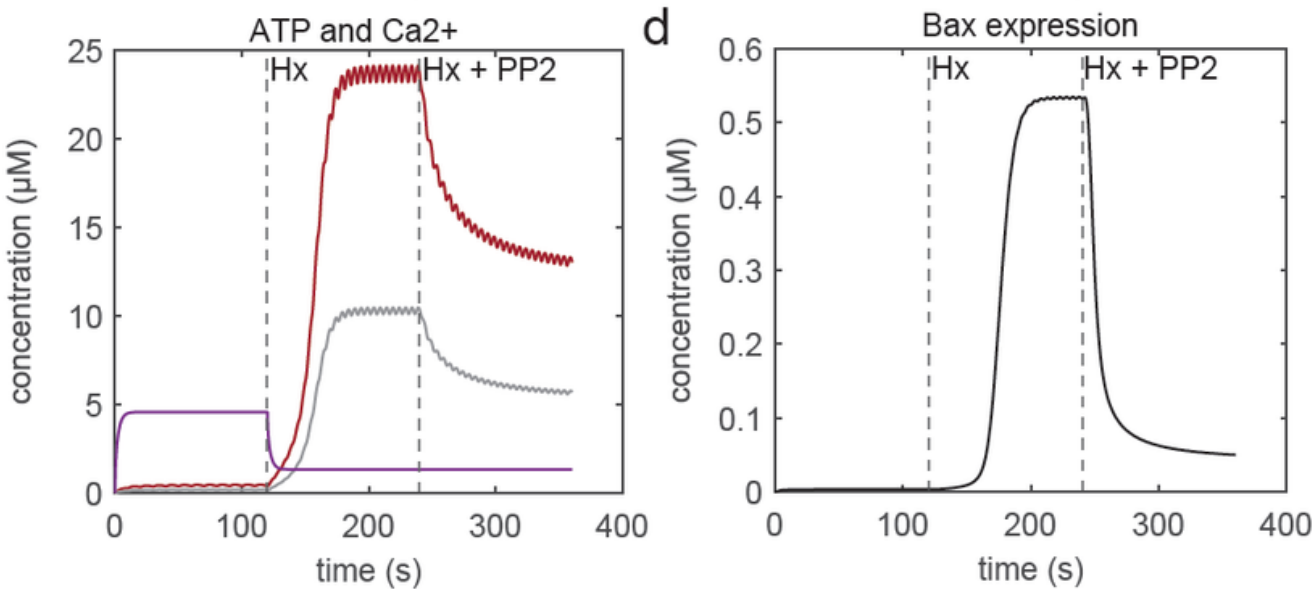

\section{Figure 4}

Ca2+/CaM-Src kinase model validation. a. Simulation of our model yields activated Src dynamics b. activated CaMKK2 (blue) and CaMKIV (cyan) c. cytoplasmic (maroon) and nuclear Ca2+ (grey) and d. Bax over simulation timecourse 
a
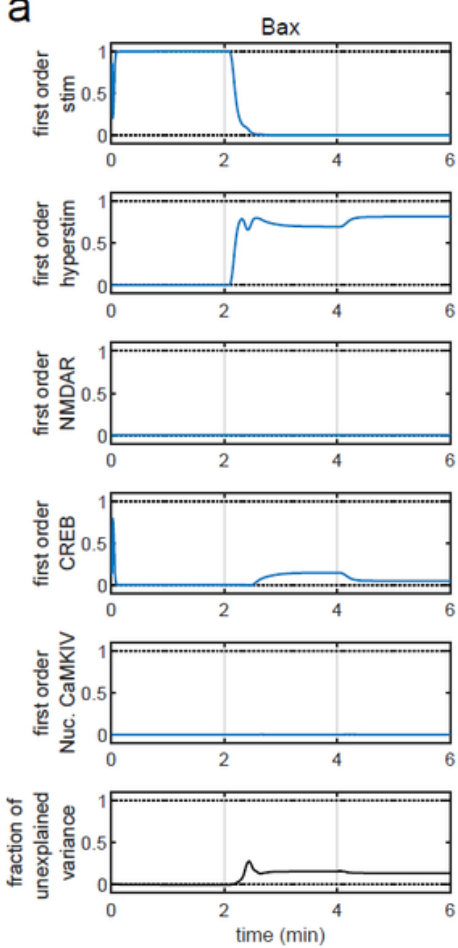

b
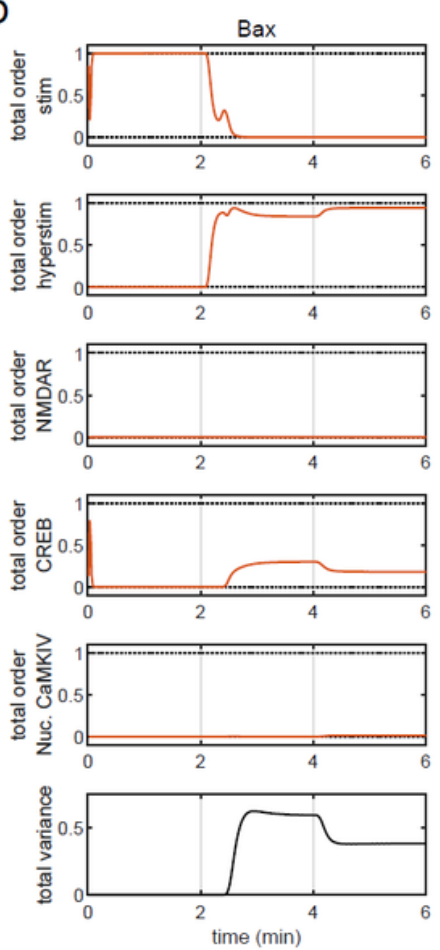

C
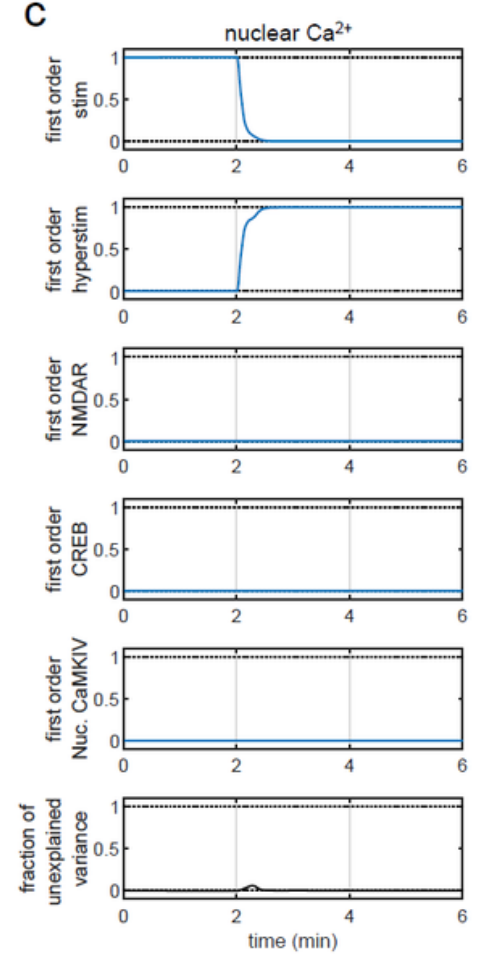

d
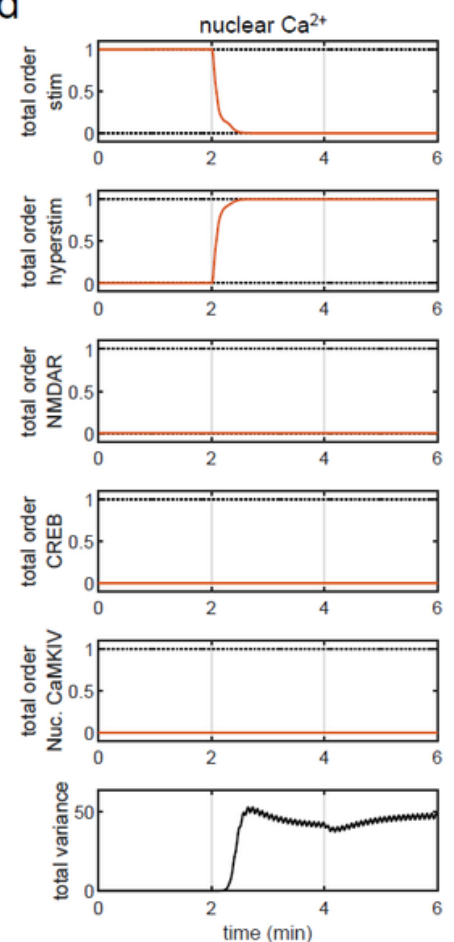

Figure 5

Global sensitivity analysis (GSA) of the Ca2+/CaM-Src model. Input parameters include "stim" (row 1 , normal glutamate pulse concentration), "hyperstim" (row 2, excitotoxic glutamate pulse concentration), NMDAR (row 3), CREB (row 4), nuclear CaMKIV (row 5), and fraction of unexplained variance (row 6) a. first order Sobol indices for Bax expression b. total order Sobol indices for Bax expression c. first order Sobol indices for nuclear $\mathrm{Ca} 2+$ influx and d. total order Sobol indices for nuclear $\mathrm{Ca} 2+$ influx.

a
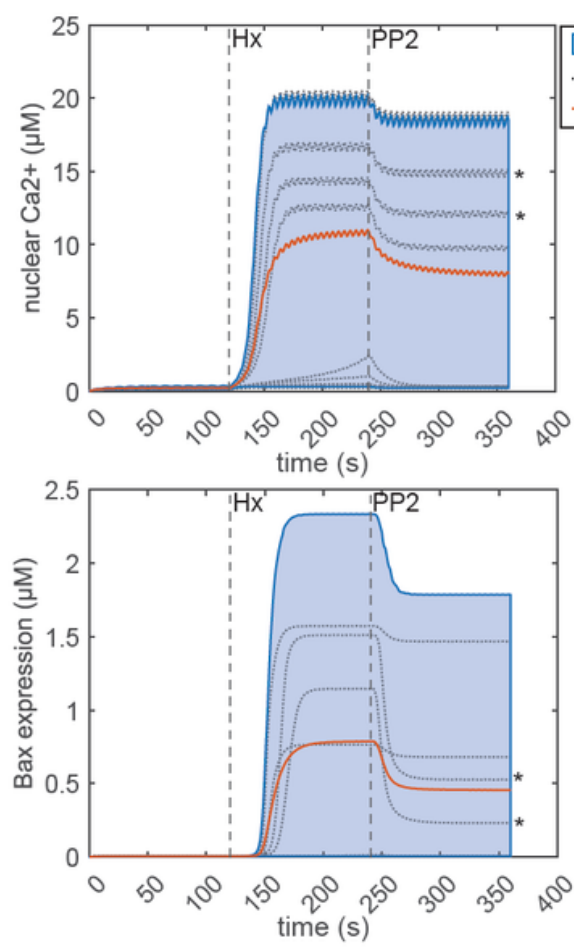

b $\max ($ nuclear $\mathrm{Ca} 2+)>10 \mu \mathrm{M}$
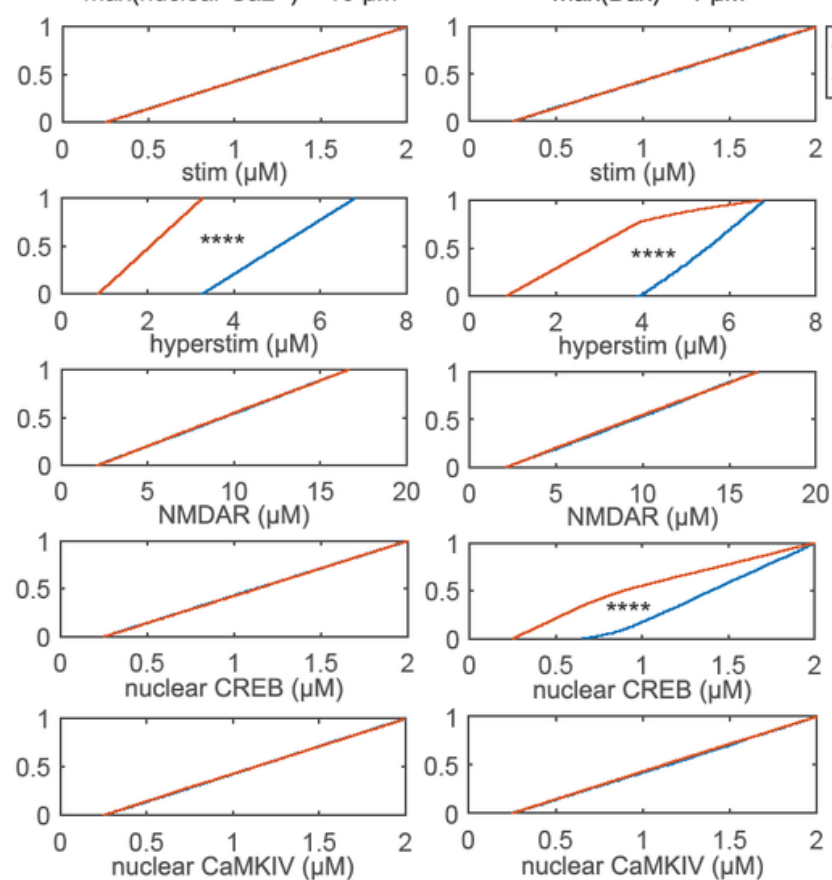


\section{Figure 6}

Multi-parametric global sensitivity analysis (MPGSA) of the Ca2+/CaM-Src model. a. All simulation runs (dotted grey lines) over timecourse; mean model simulation response (red), and the $90 \%$ region (blue) for all simulation runs for nuclear $\mathrm{Ca} 2+$ influx (top) and Bax expression (bottom). b. Cumulative distribution function plots for MPGSA with classifier $\max ($ nuclear Ca2+) $>10 \mu \mathrm{M}$ (left) and max(Bax expression) $>1$ $\mu \mathrm{M}$ (right), showing accepted (blue) and rejected (red) sample simulation values. Asterisks represents $\mathrm{P}<$ 0.0001 for Kolmogorov-Smirnov test to identify difference between accepted and rejected CDFs.

[Statistics: $(\max (\operatorname{Bax})>1 \mu \mathrm{M}$ : CaMKIV: K-S: 0.0247; P = 0.9991; CREB: K-S: 0.4137; P < 0.0001; NMDAR: P $=0.9992$, K-S: 0.0246; hyperstim: $\mathrm{P}<0.0001$; K-S: 0.7736; stim: $\mathrm{P}>0.05$; K-S: 0.0193; $\max$ (nuclear Ca2+ > $10 \mu \mathrm{M})$ : CaMKIV: $\mathrm{P}>$ 0.05, K-S: 0.0139; CREB: $\mathrm{P}>$ 0.05, K-S = 0.0136; NMDAR: $\mathrm{P}>0.05, \mathrm{~K}-\mathrm{S}=0.0153$; hyperstim: $\mathrm{P}<0.0001, \mathrm{~K}-\mathrm{S}=1$; stim: $\mathrm{P}>0.05, \mathrm{~K}-\mathrm{S}=0.0104]$.
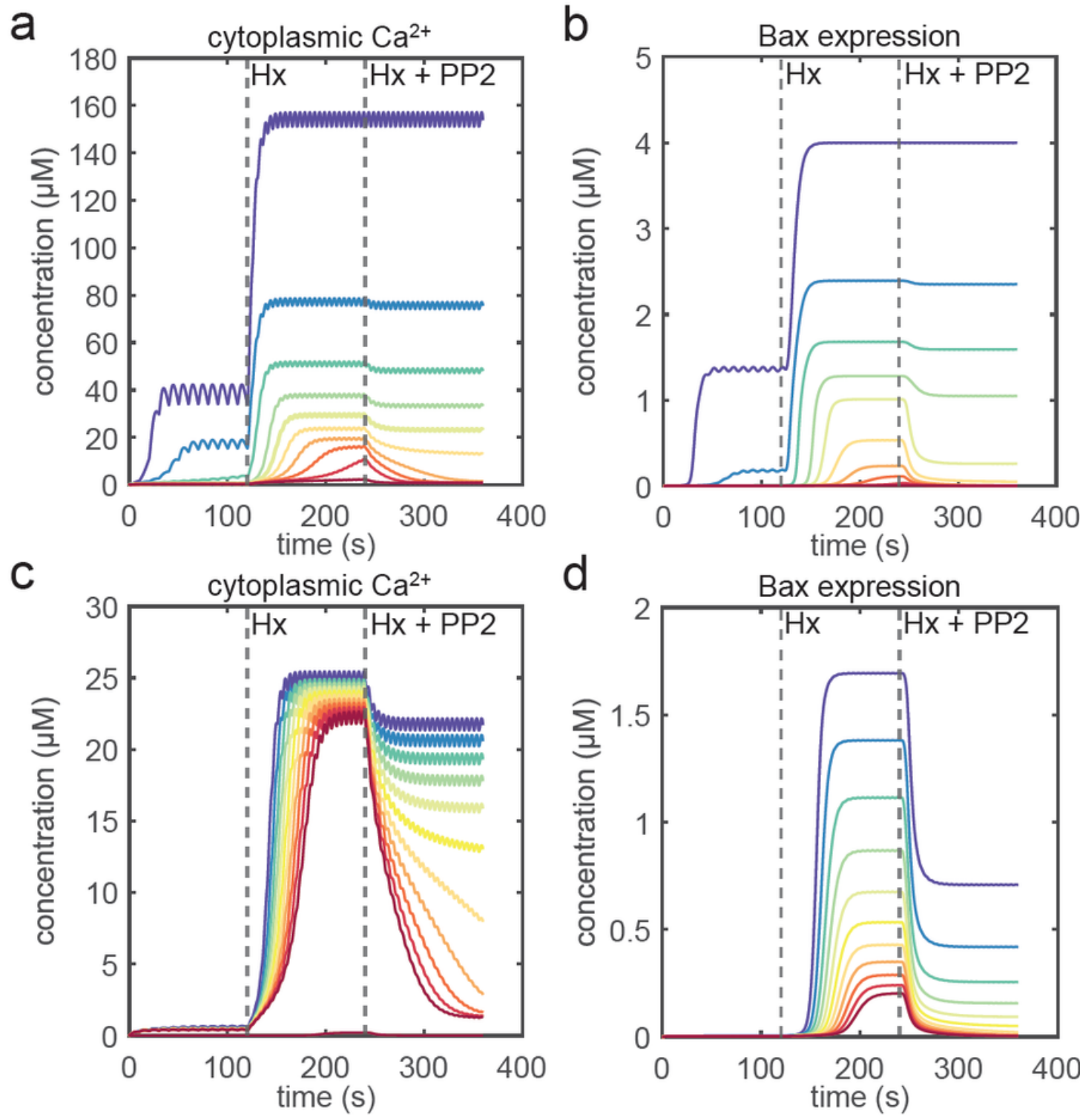

pNMDAR (activation)

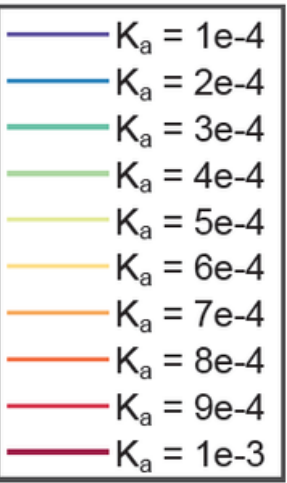

d

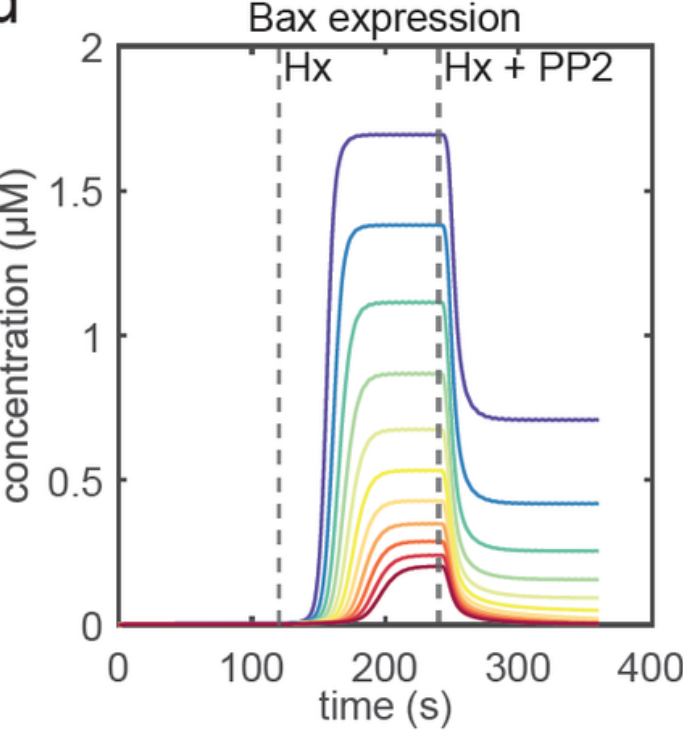

$\mathrm{Ca}^{2+} / \mathrm{CaM}$ (CaMKII activation)

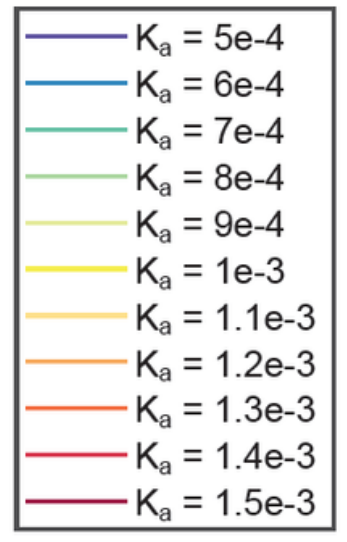

Figure 7 
Parameter scanning to identify the relative dependence of signaling components a. Dependence of NMDAR activation kinetics on simulation outcomes for $\mathrm{Ca} 2+$ influx and b. Bax expression. c. Parameter scanning of CaMKII activation kinetics on simulation outcomes for Ca2+ influx and d. Bax expression.
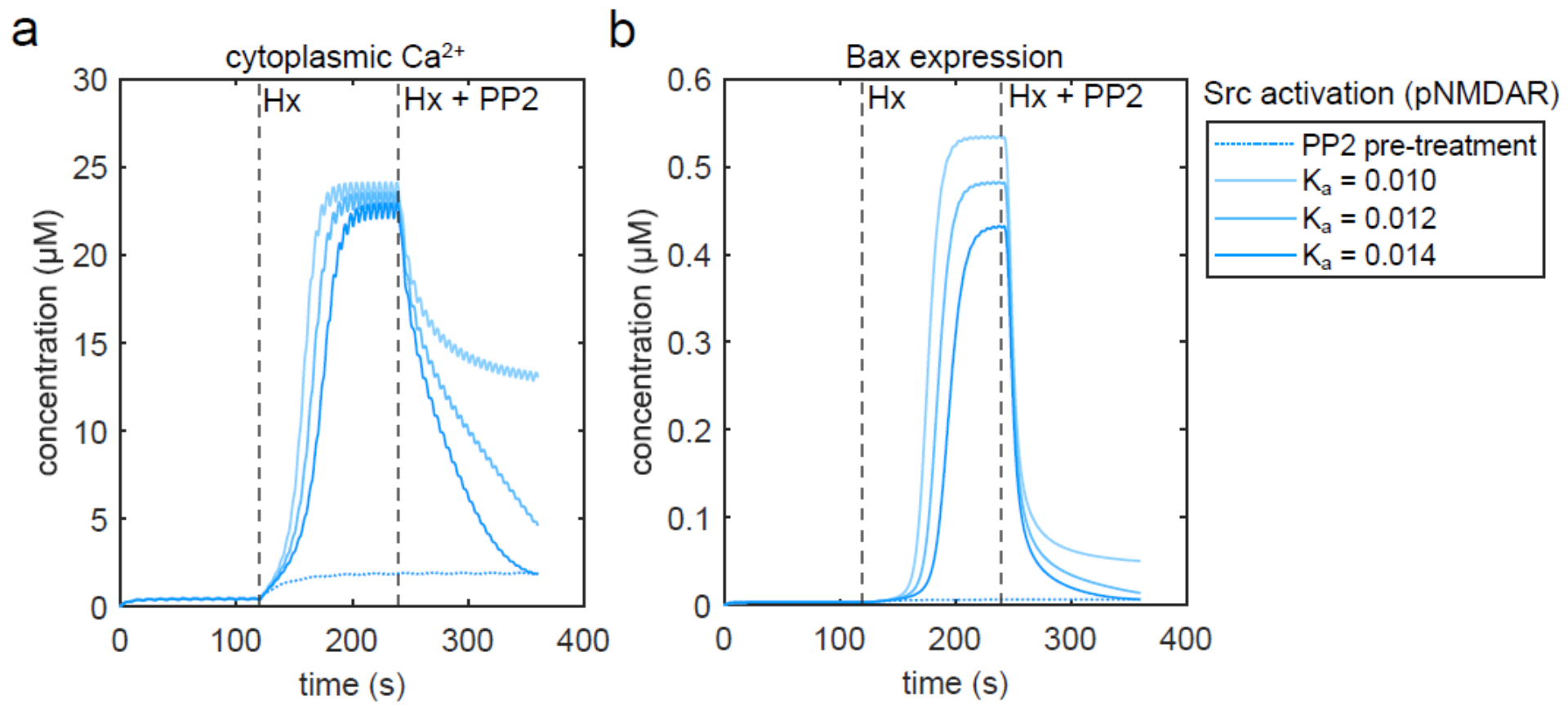

Figure 8

Effect of PP2 pre-treatment versus combination of PP2 administration following Hx and modulation of Src kinase activation of NMDARs (Ka) a. Comparison of PP2-pre-treatment (dotted line) versus Ka $=0.01$ (light tone blue), $\mathrm{Ka}=0.012$ (mid-tone blue), $\mathrm{Ka}=0.014$ (blue) on cytoplasmic $\mathrm{Ca} 2+$ influx and b. Bax expression

\section{Supplementary Files}

This is a list of supplementary files associated with this preprint. Click to download.

- KratimenosetalCaMSrcmodel.sbml

- ModelDetails.xIsx 